\title{
Rice Husk Hydrochars Prepared with Different Post- treatment Methods for the Adsorption of Dyes and Antibiotics
}

\author{
Fana Mulugeta Hagos, ${ }^{a}$ Hanxin Qian, ${ }^{\text {a Jing Di, }}$, Shengdao Shan, ${ }^{\mathrm{b}}$ Ruiqin Yang, \\ Yin $\mathrm{Li}^{\mathrm{a}}, *$ and Xikun Gai ${ }^{\mathrm{a}, *}$
}

\begin{abstract}
Hydrochars produced via hydrothermal carbonization of rice husk were post-treated using three different acids and two bases. The post-treated hydrochars were characterized using different methods and evaluated for adsorption of dyes and antibiotics from aqueous solutions. The posttreated hydrochars had carbon and oxygen contents in the range of $37.4 \%$ to $44.7 \%$ and $29.9 \%$ to $38.6 \%$, respectively, and their surfaces were rich in oxygen-containing functional groups and negative surface charges. Post-treatment remarkably influenced the physico-chemical properties of the hydrochars' surfaces. All post-treated hydrochars could adsorb the model organics from aqueous solutions with the highest adsorption amount of 327, 353, 336, and $309 \mathrm{mg} / \mathrm{g}$ for Congo red, berberine hydrochloride, tetracycline, and acridine orange, respectively, at 0.3 $\mathrm{mg} / \mathrm{mL}$ and $25^{\circ} \mathrm{C}$. The combined effects of functional groups, surface area, and negative surface charge of the hydrochars could assist in the adsorption of organics. The Langmuir-isotherm model provided a good fit for the adsorption of acridine orange, tetracycline, and berberine hydrochloride on the selected hydrochars, while the adsorption of Congo red generated linear isotherms indicating a partition-involved mechanism. The adsorption of the organics onto the hydrochars is a spontaneous and mainly physical adsorption process with a quite fast adsorption rate.
\end{abstract}

DOI: 10.15376/biores.17.1.725-749

Keywords: Hydrochar; Post-treatment; Adsorption; Dye; Antibiotic

Contact information: a: Zhejiang Provincial Key Lab for Chemical and Biological Processing Technology of Farm Product, School of Biological and Chemical Engineering, Zhejiang University of Science and Technology, Hangzhou 310023, Zhejiang, China; b: Key Laboratory of Recycling and Eco-treatment of Waste Biomass of Zhejiang Province, Zhejiang University of Science and Technology, Hangzhou 310023, Zhejiang, China; *Corresponding authors: cherryli1986@126.com (Y. Li); gaixikun@163.com (X. Gai)

\section{INTRODUCTION}

Water contamination caused by dyes and pharmaceuticals is a significant threat to human health and the environment (Chawla et al. 2017; Oladipo and Ifebajo 2018). Dyes are organic compounds, mainly discharged from textile industries, which are considered toxic, mutagenic, and carcinogenic for aquatics, animals, and human beings (Chawla et al. 2017; Zbair et al. 2018). Likewise, pharmaceuticals, such as antibiotics widely used in the human therapy and farming industries, are mainly discharged from pharmaceutical industries, agricultural runoff, and municipal wastewater treatment plants (Ren et al. 2011; Gao et al. 2012). The spread of those compounds can lead to acute and chronic toxicity to all living things, develop microbial resistance genes, and cause allergies in humans 
(Oladipo and Ifebajo 2018). Therefore, removing those dyes and antibiotics from wastewater is essential to protect aquatics, animals, and humans.

Various techniques such as chemical precipitation, membrane filtration, coagulation and flocculation, adsorption, and biodegradation have been applied to remove water contaminants; among them, adsorption is a widely used process to treat wastewater due to its easy operation, cost-effectiveness, significant removal efficiency, and high adsorption rate (Azimi et al. 2017; Darban et al. 2020; Jian et al. 2018; Li et al. 2019b; MRidha et al. 2020). Carbonaceous materials derived from waste biomass could provide good adsorption capabilities for water pollutants such as organics and heavy metals. Hydrochar is a carbon-rich solid derived from dry/wet biomass waste through hydrothermal carbonization (HTC), a thermochemical conversion process using water as a reaction medium, at a temperature of 150 to $350{ }^{\circ} \mathrm{C}$, and autogenous pressure (Jian et al. 2018; Zhang et al. 2019a). During HTC, biomass undergoes structural rearrangement by degrading into solid, liquid (bio-oil mixed with water), and gaseous products (mainly $\mathrm{CO}_{2}$ ). The liquid and gaseous fractions from hydrothermal carbonization can be recycled as fuels or sources of platform molecules (Wang et al. 2020). The solid product, hydrochars, is regarded as the main product of HTC; it can be used for carbon sequestration, soil amelioration, bioenergy production, and wastewater pollution remediation (Fang et al. 2018). In addition, hydrochars have been applied as adsorbents to remove organic contaminants from water through hydrogen bonds, ion exchange, electron donor-acceptor interactions, and hydrophobic interactions due to their diverse functional groups (Ambaye et al. 2020). The application of hydrochar for the adsorptive removal of organics from aqueous solutions has been wildly reported. Jian et al. (2018) showed that rice husk hydrochar produced at $200{ }^{\circ} \mathrm{C}$ had a higher sorption capacity for methylene blue than rice husk pyrochar prepared at $650{ }^{\circ} \mathrm{C}$. Parshetti et al. (2014) demonstrated that hydrochar prepared from food waste could effectively adsorb acridine orange and rhodamine $6 \mathrm{G}$ dyes from contaminated water. However, the adsorption capacity of hydrochar is limited because it lacks strong binding sites and has a relatively low surface area and pore volume, which inhibit its applications as an effective adsorbent (Fang et al. 2018). Thus, surface modification could be a potential method to improve the adsorption performance of hydrochar.

Modification with acids, oxidizing agents, and bases has been found to provide a higher surface area, larger pore volume, and more oxygenated functional groups on the hydrochar surface, which further influences its adsorption performance (Fang et al. 2018; Zhang et al. 2019b). For instance, after potassium hydroxide modification, the aromatic and oxygen-containing functional groups of sawdust, wheat straw, and corn stack hydrochars were increased, which resulted in approximately 2 to 3 times higher cadmium sorption capacity (Sun et al. 2015).

Post-treatment is a simple approach to prepare modified hydrochars for effective removal of contaminants. Different chemicals and their concentrations in post-treatment can notably affect the hydrochars' characteristics. However, the effects of different acids (monocarboxylic acid, dicarboxylic acid, and tricarboxylic acid) and bases (strong base and weak base) with different concentrations on the physico-chemical properties of hydrochars and their adsorption properties for wastewater contaminants have not been systematically explored.

Rice husk, a byproduct of rice processing, is rich in hemicellulose, cellulose, and lignin, making it possible to be utilized as a raw material for hydrochar production (Wang 
et al. 2010; Jian et al. 2018). The objective of this study was to change the surface chemical properties of rice husk hydrochars using a post-treatment method with three acids (monocarboxylic acid $\mathrm{HNO}_{3}$, dicarboxylic acid $\mathrm{H}_{2} \mathrm{SO}_{4}$, and tricarboxylic acid $\mathrm{H}_{3} \mathrm{PO}_{4}$ ) and two bases (strong base $\mathrm{KOH}$ and weak base $\mathrm{NH}_{4} \mathrm{OH}$ ) at different concentrations for efficient adsorption of organics. The post-treated hydrochars were well characterized, and the relationship between post-treatment agents at different concentrations and the physicochemical properties of the hydrochars were considered. The adsorption capabilities of the hydrochars for two model dyes (Congo red and acridine orange) and two model antibiotics (berberine hydrochloride and tetracycline) from aqueous solutions were investigated.

\section{EXPERIMENTAL}

\section{Materials}

Rice husk was collected from Zhejiang province (China). Sulfuric acid, nitric acid, phosphoric acid, hydrochloric acid, sodium hydroxide, potassium hydroxide, and ammonium hydroxide were provided by Shanghai Lingfeng Chemical Reagent Co., Ltd. (Shanghai, China); berberine hydrochloride was purchased from Shanghai Ruida Fine Chemicals Co., Ltd. (Shanghai, China); Congo red was obtained from Tianjin Zhiyuan Chemical Reagent Co., Ltd. (Tianjin, China); acridine orange was acquired from Shanghai Yuanye Biotech Co., Ltd. (Shanghai, China); and tetracycline was purchased from Hefei Bomei Biotechnology Co., Ltd. (Hefei, China). All the chemicals were analytical reagent (AR) grade. Deionized water was used throughout the experiments.

\section{Methods}

Preparation of rice husk hydrochars

Hydrochars were prepared from rice husk using a hydrothermal treatment. Typically, $7 \mathrm{~g}$ of rice husk was mixed with $42 \mathrm{~mL}$ of water in a 100-mL autoclave reactor (Anhui Kemi Machinery Technology Co., Ltd., Hefei, China) with an internal Teflon insert. The reactor was sealed and heated at $200{ }^{\circ} \mathrm{C}$ for $3.5 \mathrm{~h}$, then cooled down to room temperature. The mixture was filtered to collect hydrochar. The obtained hydrochar was rinsed three times with ethanol and washed with deionized water until the washed water's $\mathrm{pH}$ was around 7.0 , and it was dried at $100{ }^{\circ} \mathrm{C}$ for $12 \mathrm{~h}$. The hydrochar sample without post-treatment was named as HS.

To prepare acid or base post-treated hydrochars, the obtained HS was separately placed in $20 \mathrm{~mL}$ of acid/base solutions, with a concentration in the range of 0.5 to $1.5 \mathrm{~mol} / \mathrm{L}$ in a triangle flask. The flasks were shaken at $170 \mathrm{rpm}$ for $3 \mathrm{~h}$ at $25^{\circ} \mathrm{C}$. Then, the posttreated hydrochars were washed with deionized water until the washed water's $\mathrm{pH}$ was around 7.0. The material was dried at $100{ }^{\circ} \mathrm{C}$ for $12 \mathrm{~h}$ and stored in a desiccator for later use. The post-treated hydrochars were designated as HHS, HHN, HHP, HKH, and HNH, where $\mathrm{H}$ is the abbreviation of hydrochar, $\mathrm{HS}, \mathrm{HN}, \mathrm{HP}, \mathrm{KH}$, and $\mathrm{NH}$ indicate the posttreatment agents, and the suffix number refers to the concentration. The post-treatment conditions are shown in Table 1. 
Characterization of rice husk hydrochars

Prepared hydrochars were characterized by different techniques. Ash contents were determined by burning the hydrochars at $550{ }^{\circ} \mathrm{C}$ for $3 \mathrm{~h}$ in an air atmosphere, and the values were calculated by dividing the dry mass of ash by the dry mass of rice husk hydrochar.

Table 1. Post-treatment Solutions of Rice Husk Hydrochars

\begin{tabular}{|c|c|c|}
\hline Sample & Additives & Concentration (mol/L) \\
\hline HS & $\mathrm{No} \mathrm{additive}^{-}$ & - \\
\hline HHS 0.5 & $\mathrm{H}_{2} \mathrm{SO}_{4}$ & 0.5 \\
\hline HHS 1 & $\mathrm{H}_{2} \mathrm{SO}_{4}$ & 1.5 \\
\hline HHS 1.5 & $\mathrm{H}_{2} \mathrm{SO}_{4}$ & 0.5 \\
\hline HHN 0.5 & $\mathrm{HNO}_{3}$ & 1.5 \\
\hline HHN 1 & $\mathrm{HNO}_{3}$ & 0.5 \\
\hline HHN 1.5 & $\mathrm{HNO}_{3}$ & 1 \\
\hline HHP 0.5 & $\mathrm{H}_{3} \mathrm{PO}_{4}$ & 1.5 \\
\hline HHP 1 & $\mathrm{H}_{3} \mathrm{PO}_{4}$ & 0.5 \\
\hline HHP 1.5 & $\mathrm{H}_{3} \mathrm{PO}_{4}$ & 1 \\
\hline HKH 0.5 & $\mathrm{KOH}$ & 1.5 \\
\hline HKH 1 & $\mathrm{KOH}$ & 0.5 \\
\hline HKH 1.5 & $\mathrm{KOH}$ & 1 \\
\hline HNH 0.5 & $\mathrm{NH}_{4} \mathrm{OH}$ & 1.5 \\
\hline HNH 1 & $\mathrm{NH}_{4} \mathrm{OH}$ & \\
\hline HNH 1.5 & $\mathrm{NH}_{4} \mathrm{OH}$ & \\
\hline
\end{tabular}

The yields (\%) were calculated by dividing the final hydrochar's dry mass by the dry mass of the original feedstock. The elemental (carbon, C; hydrogen, H; sulfur, S; and nitrogen, N) compositions were analyzed with a Vario Micro Cube elemental analyzer (Elementar, Langenselbold, Germany). The oxygen, O, content was calculated by subtracting $\mathrm{C}, \mathrm{H}, \mathrm{N}, \mathrm{S}$, and ash contents from the dry mass of the hydrochars. The sample's functional groups were examined using Fourier transform infrared spectroscopy (Bruker Vertex 70 FT-IR spectrometer, Bruker, Billerica, MA, USA). The samples' pore structure characteristics were determined by $\mathrm{N}_{2}$ adsorption at $77 \mathrm{~K}$ on a sorptometer Quantachrome Autosorb iQ apparatus (Quantachrome Instruments, Boynton Beach, FL, USA). A Hitachi S3700 scanning electron microscope (SEM) (Hitachi, Tokyo, Japan) was used to study the surface morphology of the hydrochars. Thermogravimetric analysis (TGA) was performed on a thermal gravimetric analyzer (NETZSCH STA 449F3) with a $10^{\circ} \mathrm{C} / \mathrm{min}$ heating rate. Zeta potential values of all samples were analyzed with a Malvern Zetasizer nano series analyzer (Malvern Instruments Ltd., Worcester, UK). X-ray diffraction (XRD) was completed using an X-ray diffractometer (Ultima IV, Kuraray Co., Tokyo, Japan) by $\mathrm{Cu}$ $\mathrm{K} \alpha$ radiation source at $40 \mathrm{~mA}$ and $40 \mathrm{kV}$ conditions. Speciation and distribution of $\mathrm{C}$ on the hydrochars' surfaces were determined by X-ray photoelectron spectroscopy (Thermo Scientific K-alpha, Thermo Fisher Scientific, Waltham, MA, USA).

\section{Batch adsorption experiment}

The batch adsorption experiments were performed by placing $0.01 \mathrm{mg}$ of the hydrochars in $20 \mathrm{~mL}$ of organic solutions with known initial concentrations, $C_{0}(\mathrm{mg} / \mathrm{mL})$ in $100-\mathrm{mL}$ triangle flasks, and the flasks were shaken at $170 \mathrm{rpm}$ for $8 \mathrm{~h}$ at 25,35 , and $45^{\circ} \mathrm{C}$. The equilibrium concentrations $C_{\mathrm{e}}(\mathrm{mg} / \mathrm{mL})$ of Congo red, acridine orange, berberine hydrochloride, and tetracycline were determined using a UV-vis spectrophotometer 
(Shanghai Tensuc Lab Instruments Manufacturing, Shanghai, China) at their maximum detection wavelength of 499, 490.5, 345, and $355 \mathrm{~nm}$, respectively. The initial $\mathrm{pH}$ was adjusted with $0.1 \mathrm{~mol} / \mathrm{L} \mathrm{HCl}$ and $0.1 \mathrm{~mol} / \mathrm{L} \mathrm{NaOH}$ solutions, and measured with special $\mathrm{pH}$ indicator strips. Adsorption capacities $Q_{\mathrm{e}}(\mathrm{mg} / \mathrm{g})$ were calculated as,

$$
Q_{\mathrm{e}}=\left(C_{0}-C_{\mathrm{e}}\right) \times \frac{V}{m}
$$

where $V(\mathrm{~mL})$ is the suspension volume and $m(\mathrm{~g})$ is the dry adsorbent mass.

\section{Adsorption kinetics}

Adsorption kinetics tests were carried out in 100-mL triangle flasks, in which 0.05 $\mathrm{mg}$ of the selected hydrochars were added to $20 \mathrm{~mL}$ of $0.3 \mathrm{mg} / \mathrm{mL}$ of four different organic solutions. The flasks were shaken at $170 \mathrm{rpm}$, in a time range of 0 to $4 \mathrm{~h}$ at 25,35 , and 45 ${ }^{\circ} \mathrm{C}$. The concentrations of the organics in the suspensions at time $t, C_{\mathrm{t}}(\mathrm{mg} / \mathrm{mL})$, were determined after filtration. Adsorption capacities at t, $Q_{\mathrm{t}}(\mathrm{mg} / \mathrm{g})$ were calculated as:

$$
Q_{\mathrm{t}}=\left(C_{\mathrm{o}}-C_{\mathrm{t}}\right) \times \frac{V}{m}
$$

\section{RESULTS AND DISCUSSION}

\section{Characterization}

Yields, ash contents, elemental compositions, pore properties, and zeta potentials of the hydrochars are listed in Table 2 . The yields of the post-treated hydrochars were in a range of $45.2 \%$ to $59.8 \%$, which was slightly lower than the yield of rice husk hydrochar prepared in pure water (HS), indicating that the post-treatment agents should only react with the outer surface of the hydrochars and thus lead to a slight mass loss. In contrast, the hydrochars post-treated with potassium hydroxide (HKHs) showed the lowest yields among all the samples. Hydrochar contains organic components such as organic acids, phenols, and humic-like substances with carboxylic, phenolic, and lactonic groups, and inorganic components such as silica and alumina (Tsechansky and Graber 2014; Chen et al. 2018). Although most of these organic matters are water soluble, some could still be remained in the pore structures or adsorbed on the surface of the hydrochars (Yan et al. 2018). When contacted with potassium hydroxide, a strong base, these substances could be dissolved out, then eliminated by the water washing step, resulting in lower yields of HKHs. However, different concentrations of the post-treatment agents did not drastically affect the yields of the hydrochars.

The ash contents of the post-treated hydrochars except HKHs were in the range of $20.6 \%$ to $23.8 \%$, higher than the ash content of HS (20.5\%). The slight increase might be attributed to the remaining $\mathrm{S}, \mathrm{P}$, and $\mathrm{N}$ elements from the post-treatment agents $\mathrm{of}_{2} \mathrm{SO}_{4}$, $\mathrm{H}_{3} \mathrm{PO}_{4}, \mathrm{HNO}_{3}$, and $\mathrm{NH}_{4} \mathrm{OH}$ on the surface of the hydrochars (Zhang et al. 2019b). In contrast, HKHs had ash contents between $7.56 \%$ and $11.1 \%$, which was much lower than that of HS, and the values decreased with the increasing concentration of potassium hydroxide. It is known that the main inorganic component of rice husk is silica oxide $\left(\mathrm{SiO}_{2}\right)$, which could react with potassium hydroxide to form water-soluble silicate; this might be the reason for the lower ash contents of HKHs (Huang et al. 2017; Nakason et al. 2018); and this result is consistent with the yield order of the hydrochars. 
Table 2. Yields, Ash Content, Elemental Composition, Pore Properties, and Zeta Potential of All Hydrochars

\begin{tabular}{|c|c|c|c|c|c|c|c|c|c|c|c|}
\hline \multirow[b]{2}{*}{ Samples } & \multirow{2}{*}{$\begin{array}{l}\text { Yield } \\
(\%)\end{array}$} & \multirow{2}{*}{$\begin{array}{c}\text { Ash } \\
\text { Content } \\
(\%)\end{array}$} & \multicolumn{5}{|c|}{ Elemental Composition } & \multicolumn{3}{|c|}{ Pore Properties } & \multirow[b]{2}{*}{$\begin{array}{c}\text { Zeta Potentia } \\
(\mathrm{mV})\end{array}$} \\
\hline & & & $\mathbf{N} \%$ & $\mathbf{C} \%$ & $\mathrm{H} \%$ & $0 \%$ & $\mathrm{~S} \%$ & $\begin{array}{c}\text { BET Surface } \\
\text { Area }\left(\mathrm{m}^{2} / \mathrm{g}\right)\end{array}$ & $\begin{array}{l}\text { Pore Volume } \\
\left(\mathrm{cm}^{3} / \mathrm{g}\right)\end{array}$ & $\begin{array}{l}\text { Pore Diameter } \\
(\mathrm{nm})\end{array}$ & \\
\hline HHS 0.5 & 58.03 & 21.76 & 0.25 & 39.55 & 5.06 & 34.26 & 0.09 & 11.27 & 0.028 & 8.752 & -29.17 \\
\hline HHS 1 & 55.80 & 20.59 & 0.27 & 39.66 & 5.02 & 38.42 & 0.06 & 11.52 & 0.029 & 8.706 & -31.30 \\
\hline HHS 1.5 & 55.95 & 20.82 & 0.22 & 39.22 & 4.91 & 38.59 & 0.04 & 11.49 & 0.029 & 8.789 & -36.40 \\
\hline HHN 0.5 & 58.68 & 21.85 & 0.22 & 39.61 & 4.88 & 38.63 & 0.01 & 11.38 & 0.028 & 8.842 & -31.6 \\
\hline HHN 1 & 56.12 & 22.41 & 0.19 & 38.73 & 4.84 & 32.85 & 0.01 & 10.97 & 0.030 & 9.267 & -34.4 \\
\hline HHN 1.5 & 57.22 & 23.77 & 0.31 & 38.76 & 4.78 & 29.92 & 0.01 & 12.18 & 0.029 & 8.709 & -37.6 \\
\hline HHP 0.5 & 58.74 & 23.34 & 0.31 & 38.79 & 4.76 & 32.60 & 0.00 & 10.49 & 0.027 & 9.140 & -31.60 \\
\hline HHP 1 & 58.10 & 23.35 & 0.38 & 38.61 & 4.74 & 32.50 & 0.00 & 11.65 & 0.030 & 8.762 & -35.87 \\
\hline HHP 1.5 & 59.75 & 22.59 & 0.70 & 37.42 & 4.72 & 33.79 & 0.06 & 11.21 & 0.027 & 8.738 & -39.73 \\
\hline HKH 0.5 & 48.97 & 11.053 & 0.20 & 42.43 & 5.39 & 31.64 & 0.01 & 5.11 & 0.021 & 15.01 & -26.40 \\
\hline HKH 1 & 47.13 & 9.201 & 0.20 & 43.20 & 5.41 & 33.47 & 0.01 & 2.38 & 0.013 & 19.44 & -33.00 \\
\hline HKH 1.5 & 45.15 & 7.563 & 0.25 & 44.69 & 5.47 & 32.99 & 0.01 & 1.74 & 0.009 & 17.68 & -41.67 \\
\hline HNH 0.5 & 58.93 & 22.32 & 0.25 & 38.37 & 4.84 & 32.49 & 0.00 & 11.92 & 0.030 & 8.446 & -21.90 \\
\hline HNH 1 & 58.16 & 23.03 & 0.23 & 38.65 & 4.74 & 32.18 & 0.00 & 11.85 & 0.028 & 8.777 & -23.70 \\
\hline HNH 1.5 & 57.43 & 22.26 & 0.22 & 39.65 & 4.88 & 32.67 & 0.00 & 11.84 & 0.027 & 8.467 & -25.40 \\
\hline HS & 61.44 & 20.46 & 0.21 & 38.38 & 4.72 & 32.04 & 0.00 & 11.57 & 0.027 & 8.637 & -16.53 \\
\hline
\end{tabular}


From the elemental analysis results summarized in Table 2, the main components of all the hydrochar samples were carbon (37.4\% to $44.7 \%)$ and oxygen $(29.9 \%$ to $38.6 \%$ ). Post-treated hydrochars, except HKHs, do not reveal major differences in their elemental compositions.

The HKHs obviously presented higher carbon contents than that of HS, which could still be due to the high removal of ash contents from these hydrochar samples (Chen et al. 2018), and it is easy to understand the rise in carbon content of the hydrochars with increasing concentration of potassium hydroxide. As can be seen from the pore properties listed in Table 2, the hydrochars prepared in this study had Brunauer Emmett Teller (BET) surface areas in the range of 1.74 to $12.18 \mathrm{~m}^{2} / \mathrm{g}$, pore volumes ranging from 0.009 to 0.03 $\mathrm{cm}^{3} / \mathrm{g}$, and average pore diameters from 8.45 to $19.44 \mathrm{~nm}$. Post-treatment did not influence the surface area, pore-volume, and pore diameter of the hydrochar samples except for the HKHs, which further confirmed that modification should only occur on the hydrochars' outer surfaces during the post-treatment process. The HKHs showed the lowest BET surface areas and pore-volumes but the largest pore diameters among all the hydrochar. Potassium hydroxide can dissolve small molecular humic substances, which could enter into the micropores of the hydrochars during post-treatment, cause blockage of the micropores and thus result in lower surface areas but larger average pore diameters of the hydrochars (Sun et al. 2015; Yan et al. 2018).

The zeta potential values (Table 2 ) revealed that all the hydrochars had moderately negative surfaces, and more negative surface charges were observed on the post-treated hydrochars $(-21.9 \mathrm{mV}$ to $-41.7 \mathrm{mV})$ than that of $\mathrm{HS}(-16.5 \mathrm{mV})$. In addition, the zeta potential value became more negative with the concentration increment of all the posttreatment agents, which could be due to the introduction of additional oxygen-containing groups onto the surface of the hydrochars at higher acid or base concentrations (Deng et al. 2019). These results suggest post-treated hydrochars as suitable sorbents for cation adsorption through electrostatic interactions (Liu et al. 2019).

Figure 1 displays FTIR spectra of the hydrochar samples. All the hydrochar shared some of the same functional groups such as $\mathrm{O}-\mathrm{H}\left(3424 \mathrm{~cm}^{-1}\right), \mathrm{C}-\mathrm{H}$ hydro aromatic structure (between 2924 and $\left.3015 \mathrm{~cm}^{-1}\right), \mathrm{C}=\mathrm{O}\left(1607 \mathrm{~cm}^{-1}\right), \mathrm{C}=\mathrm{C}$ of aromatic rings $\left(1546 \mathrm{~cm}^{-1}\right), \mathrm{C}$ $\mathrm{O}\left(1103 \mathrm{~cm}^{-1}\right)$, and $\mathrm{C}-\mathrm{C}\left(730 \mathrm{~cm}^{-1}\right)$. The hydrochar surfaces were rich in oxygen-containing groups, which could assist in chemical or semi-chemical adsorptions for organics. All of the functional groups on the hydrochars were maintained after post-treatment. 


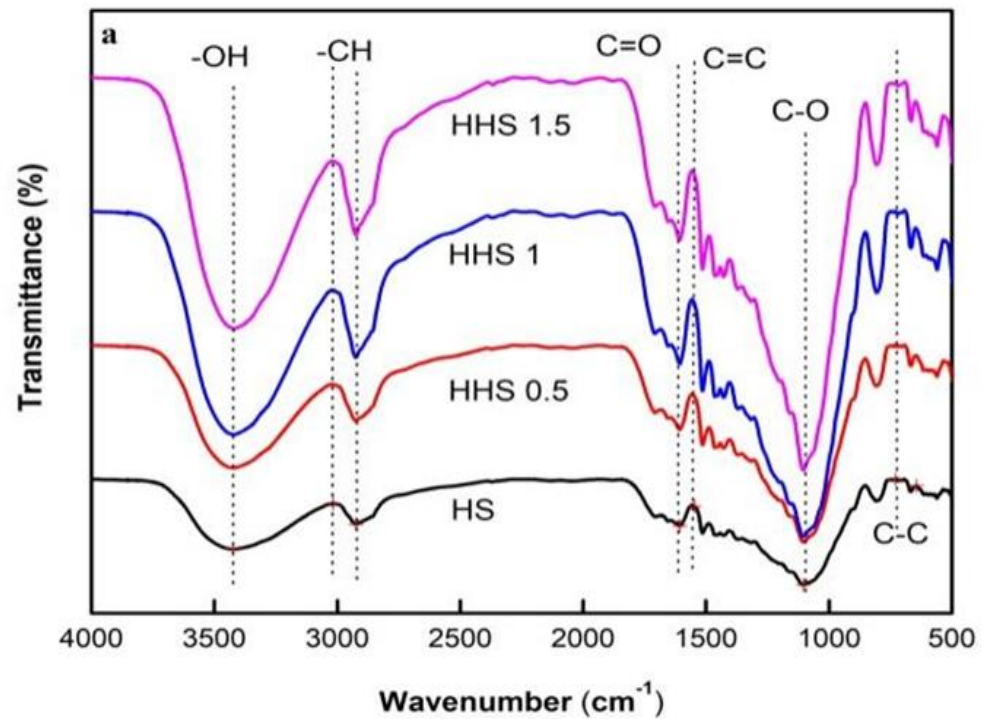

Fig. 1A. FTIR spectra of (a) HS, HHS (0.5 to 1.5); (b) HS, HHN (0.5 to 1.5); (c) HS, HHP (0.5 to 1.5); (d) HS, HKH (0.5 to 1.5); and (e) HS, HNH (0.5 to 1.5)

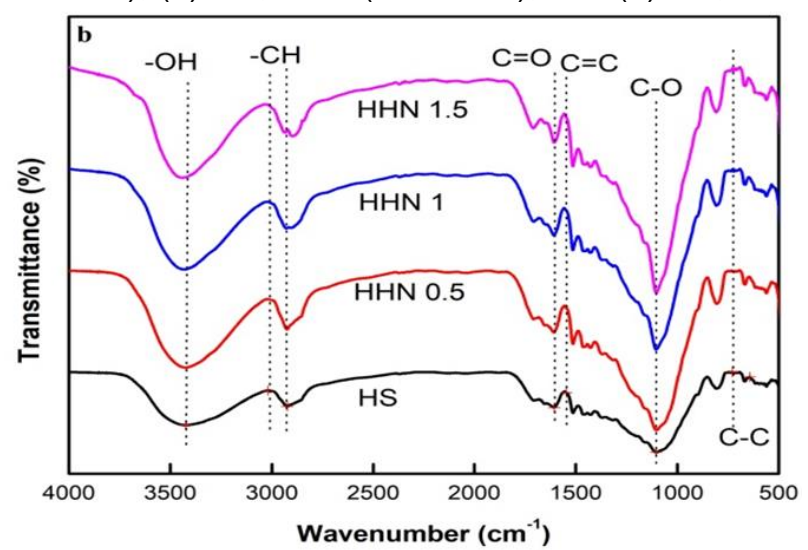

(b)

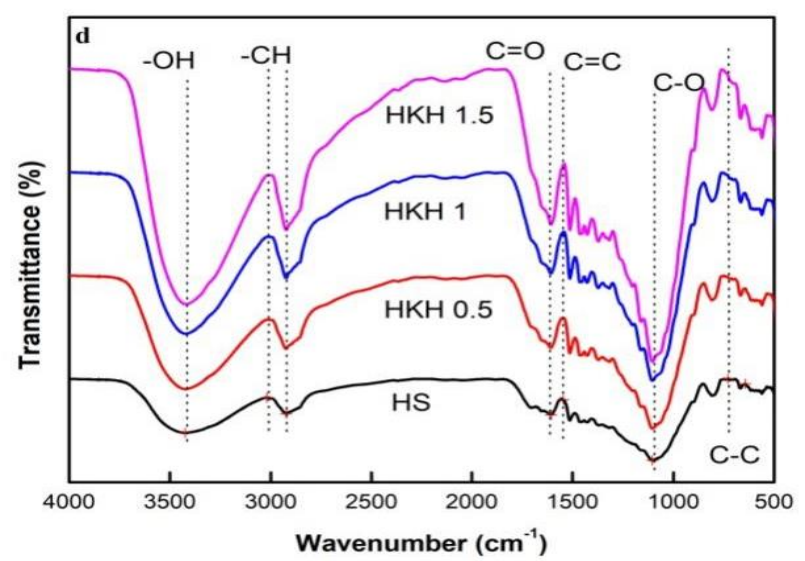

(c)
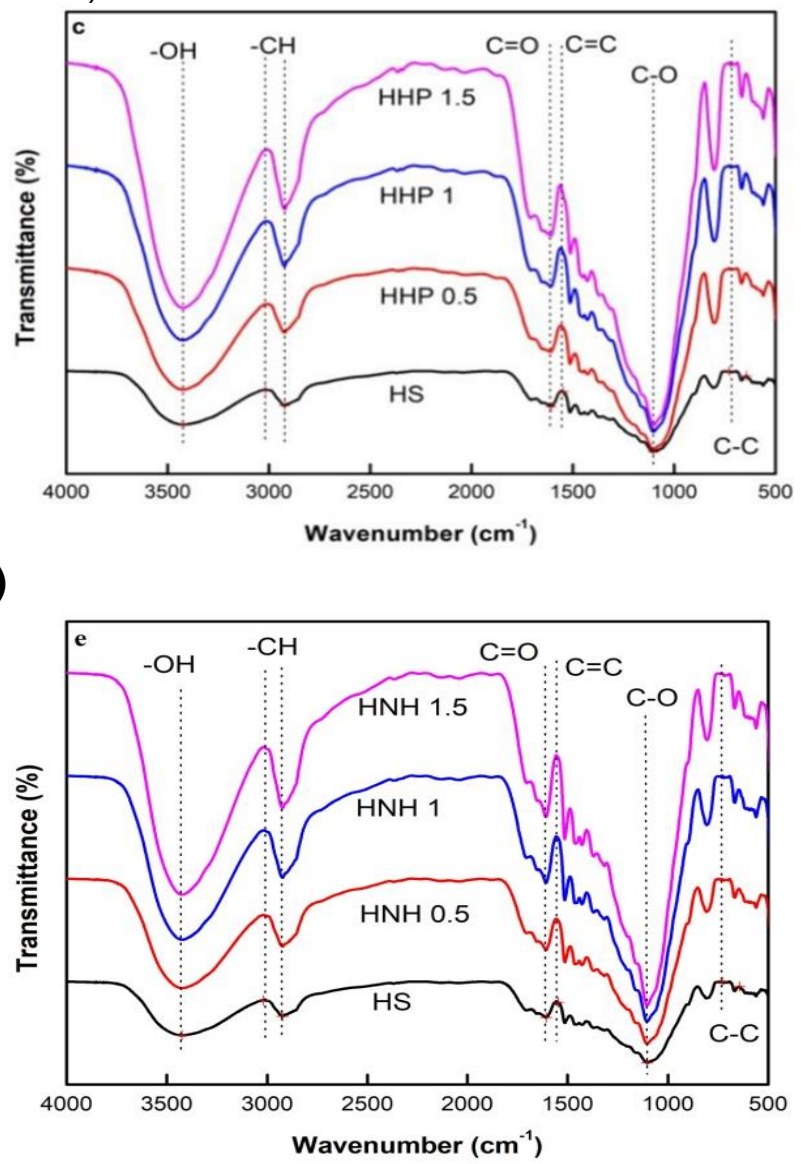

(d)

(e)

Fig. 1 (b-e). FTIR spectra of (a) HS, HHS (0.5 to 1.5); (b) HS, HHN (0.5 to 1.5); (c) HS, HHP (0.5 to 1.5$)$; (d) HS, HKH (0.5 to 1.5); and (e) HS, HNH (0.5 to 1.5)

The X-ray photoelectron spectroscopy (XPS) analysis of HS and HKH 0.5 is presented in Fig. 2. The C-1s XPS spectra of HS exhibited four peaks at 284, 286, 287, and 
$291 \mathrm{eV}$, corresponding to the carbon-based functional groups $\mathrm{C}-\mathrm{C} / \mathrm{C}-\mathrm{H}, \mathrm{C}-\mathrm{O}, \mathrm{C}=\mathrm{O}$, and $\mathrm{COO}^{-}$, respectively (Lei et al. 2016; Liu et al. 2019). Similar functional groups could be observed in both samples, while HKH 0.5 showed much higher contents of the oxygencontaining functional groups than HS, which could be favorable for forming hydrogen bonds between the adsorbent's surface and the organics to result in a higher adsorbate capacity. This result confirmed that post-treatment could change the surface chemistry of the hydrochars and might further influence their adsorption affinity for organics.

The XRD patterns of the hydrochars are illustrated in Fig. 3. All the hydrochar samples shared similar crystallographic structures, and two diffraction peaks were observed at $2 \theta=15.38^{\circ}$ and $21.92^{\circ}$, which could be assigned to the crystal cellulose structure, suggesting a low carbonization degree of the hydrochars (Petrović et al. 2016). However, these peaks weakened and became broader after post-treatment, especially at higher concentrations of the post-treatment agents, indicating a gradual decrease in cellulose crystalline during the post-treatment process (Sun et al. 2015).
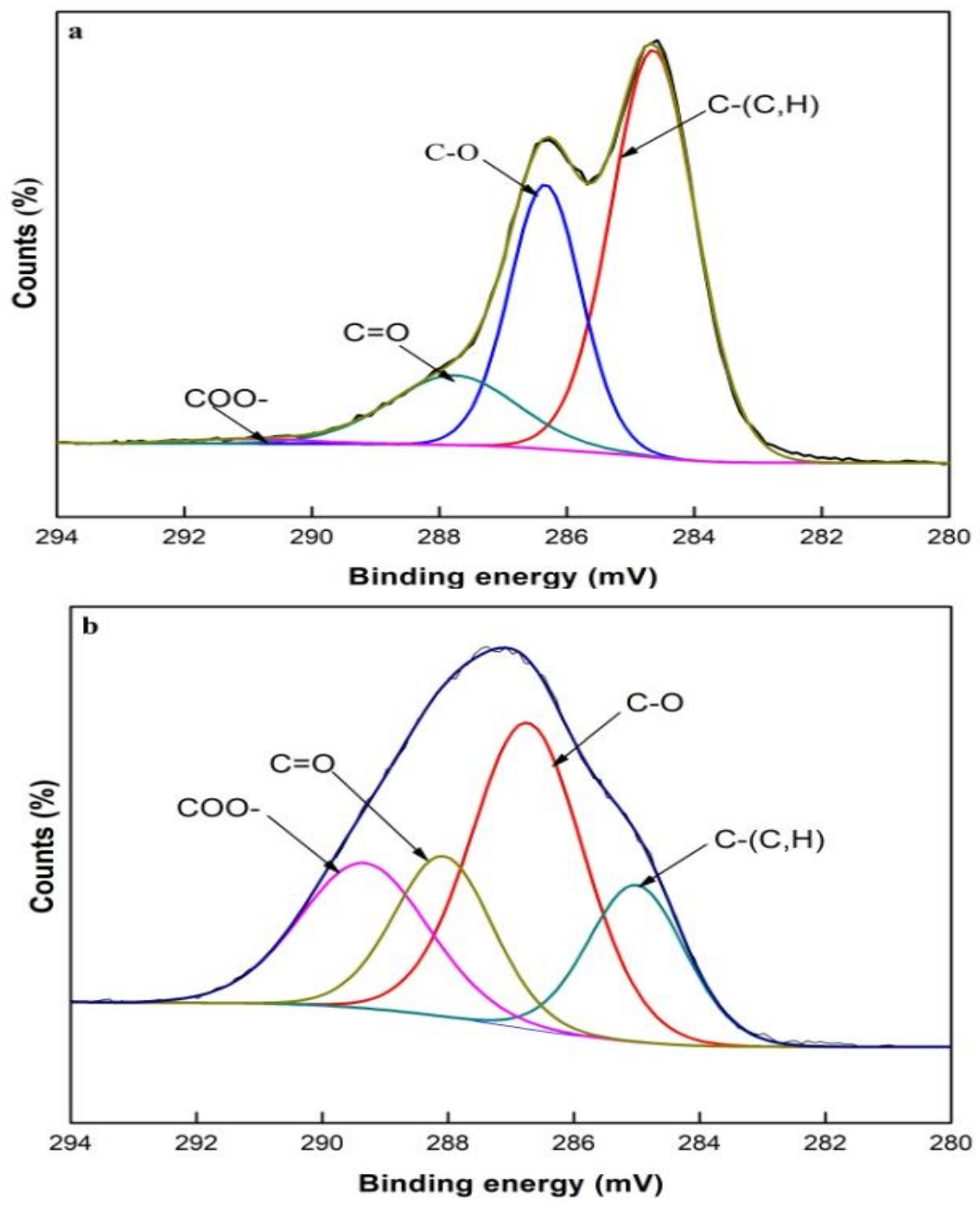

Fig. 2. C1S XPS spectra of HS (a) and HKH 0.5 (b) 

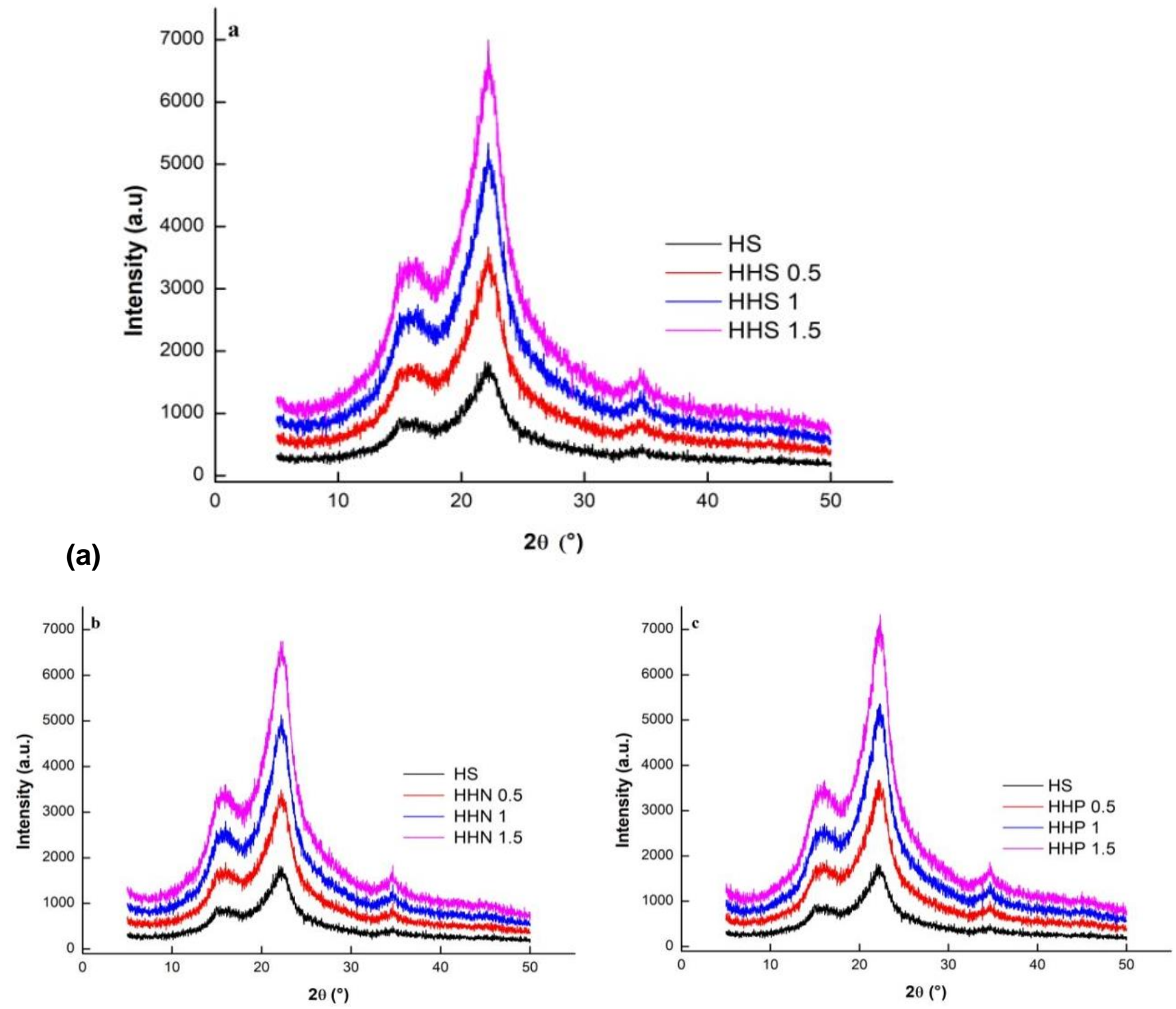

(b)

(c)
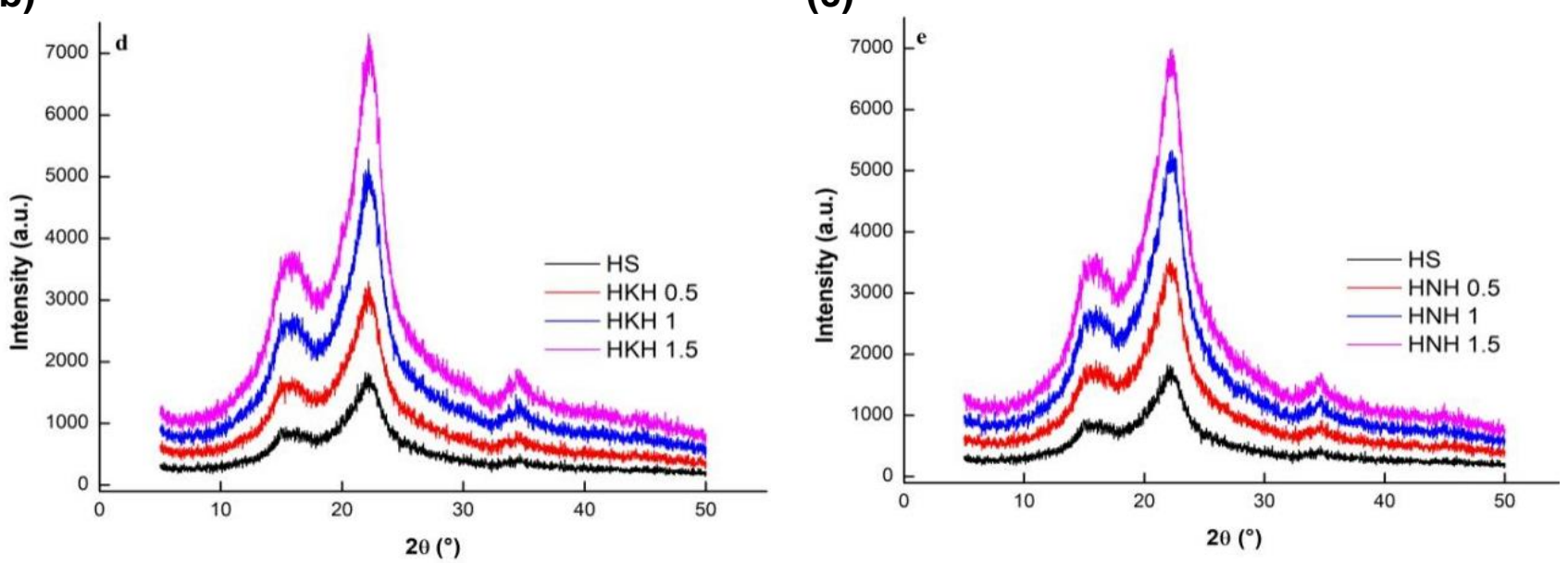

(d)

(e)

Fig. 3. XRD patterns of (a) HS, HHS (0.5 to 1.5); (b) HS, HHN (0.5 to 1.5); (c) HS, HHP (0.5 to 1.5); (d) HS, HKH (0.5 to 1.5); and (e) HS, $\mathrm{HNH}$ (0.5 to 1.5) 
The TGA and DTA curves of HS and HKH 0.5 are presented in Fig. 4. The TGA curves showed that the thermal decomposition of the two hydrochars occurred in three steps as the temperature was increased up to $946{ }^{\circ} \mathrm{C}$.
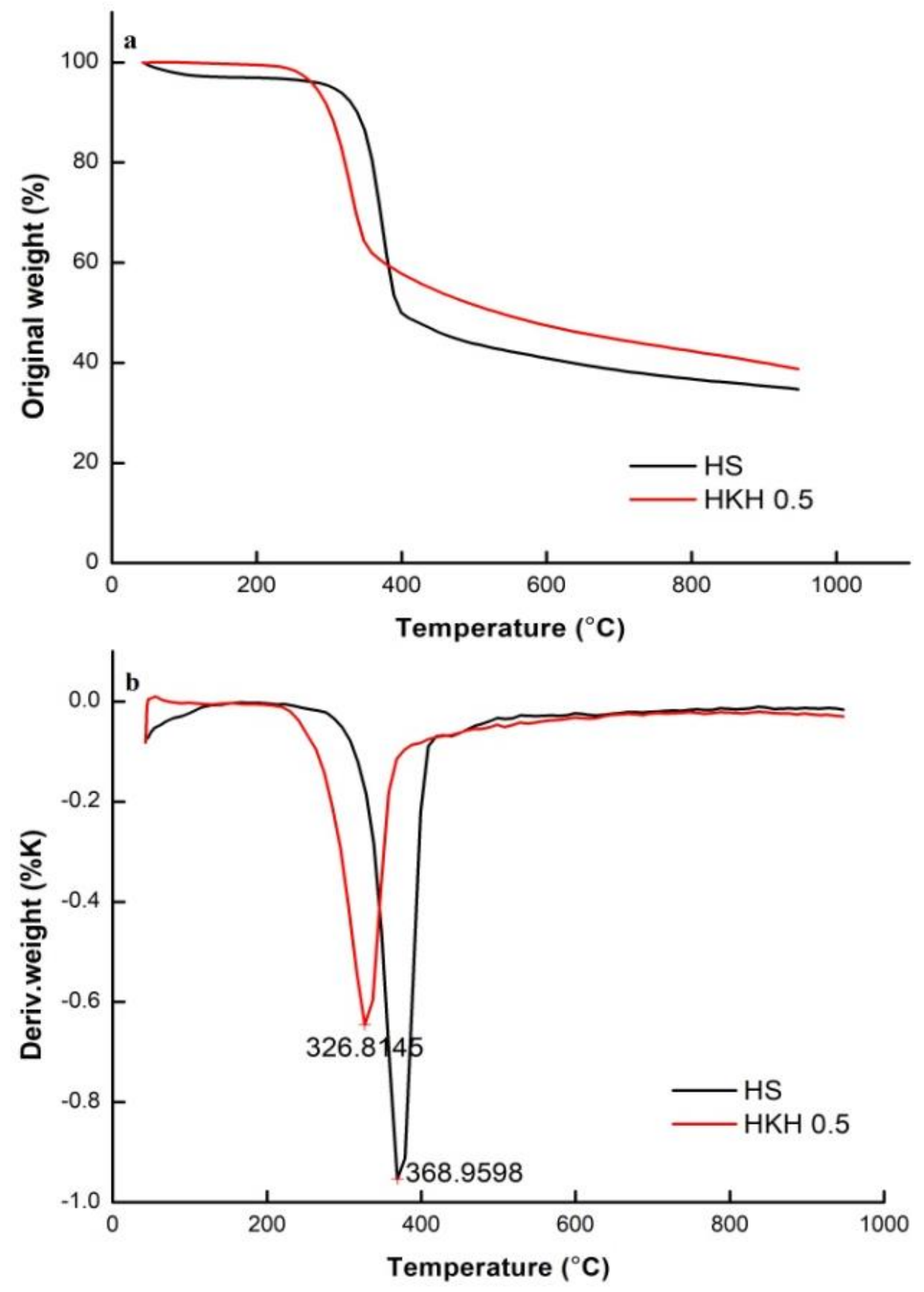

Fig. 4. TGA curves of $\mathrm{HS}, \mathrm{HKH} 0.5$ (a) and DTA curves of $\mathrm{HS}, \mathrm{HKH} 0.5$ (b)

The first step below $180{ }^{\circ} \mathrm{C}$ was related to the loss of water and volatile components. The second step exhibited the highest weight loss between $281{ }^{\circ} \mathrm{C}$ and 458 ${ }^{\circ} \mathrm{C}$, which should be attributed to the decomposition of cellulose and hemicelluloses (Parshetti et al. 2013). The last step took place from $458{ }^{\circ} \mathrm{C}$ to $945{ }^{\circ} \mathrm{C}$, which might have been caused by lignin decomposition (Shi et al. 2018). Those results revealed that 
cellulose, hemicelluloses, and lignin might still be the main components of the hydrochars. All the decomposition temperatures of HKH 0.5 started approximately $42{ }^{\circ} \mathrm{C}$ lower than HS, implying a negative impact of post-treatment on the thermal stability of hydrochar, which might be attributed to the lower crystallinity of HKH 0.5 (Fig. 3).

Figure 5 displays the SEM images of HS and HKH 0.5 to illustrate the morphology changes. The SEM image of HKH 0.5 revealed a slightly rougher surface than that of HS; the defects and cracks in the surface of HKH 0.5 could have been caused by the removal of inorganic and organic matters from the surface during the post-treatment process.
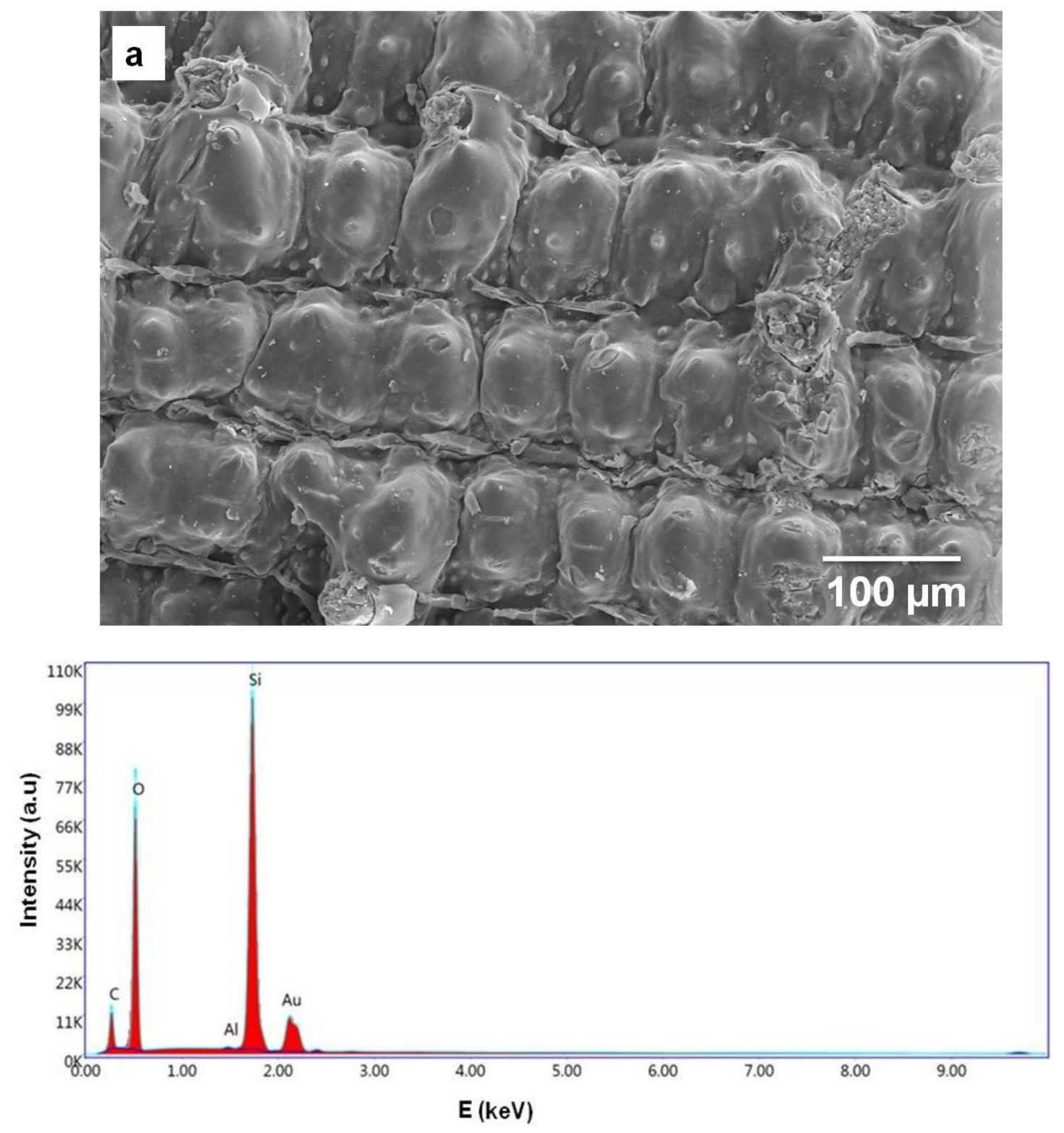

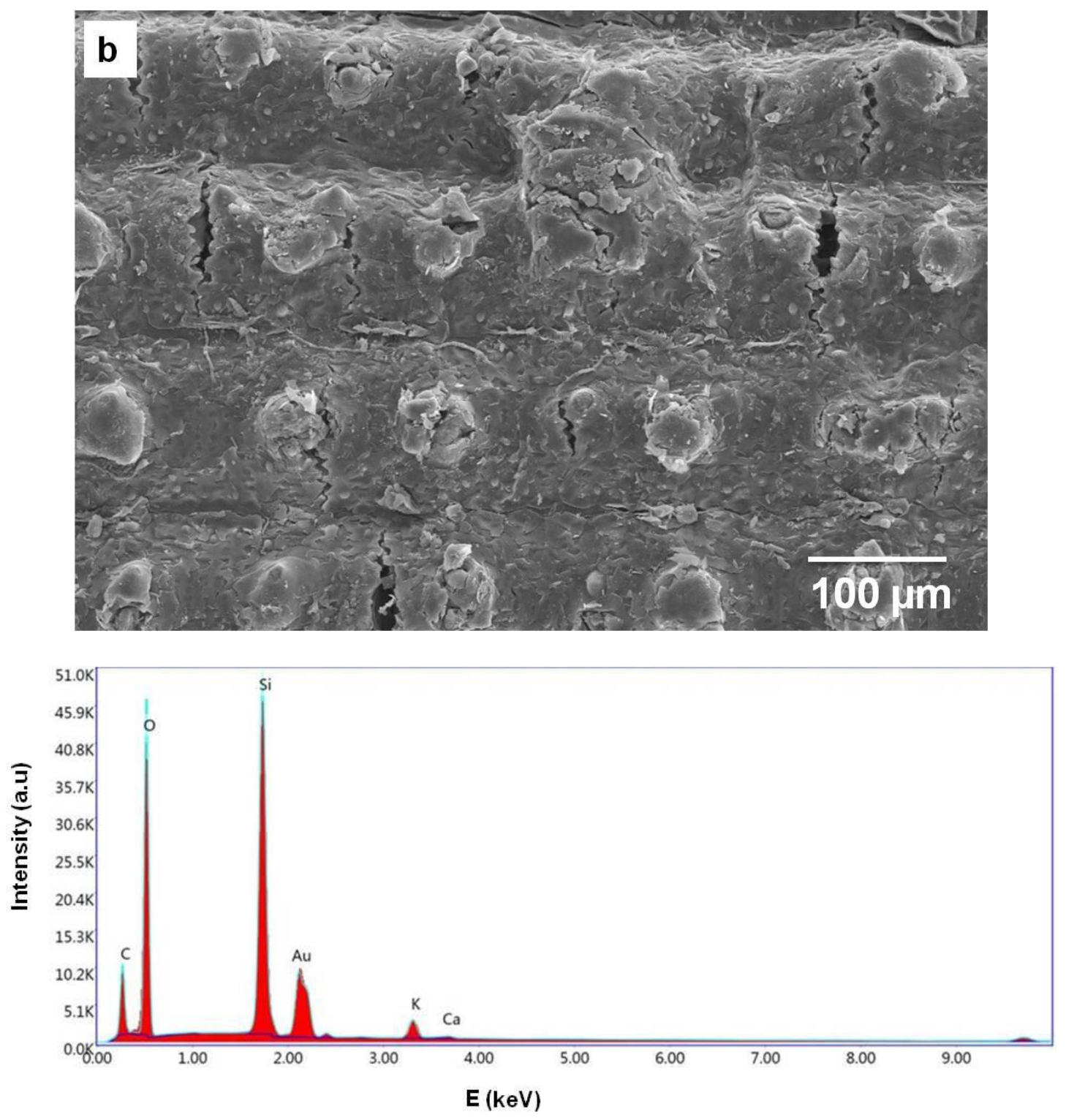

Fig. 5. SEM image and corresponding EDS spectra of (a) HS and (b) HKH 0.5

According to the energy-dispersive X-ray spectroscopy (EDS) spectra shown in Fig. 5, the surfaces of both the HS and HKH 0.5 showed the presence of $\mathrm{Si}, \mathrm{C}$, and $\mathrm{O}$. In addition, the post-treatment introduced $\mathrm{K}$ to the surface of the hydrochar, and the appearance of $\mathrm{Ca}$, and $\mathrm{S}$ on $\mathrm{HKH} 0.5$ might have been due to the etching effect of the posttreatment agent on the surface of hydrochar (Bashir et al. 2018; Zou and Yang 2019). These elements might assist the chemical and semi-chemical adsorption of organics on the hydrochar's surface.

\section{Adsorption Capacity}

Figure 6 presents the adsorption capacities of Congo red, acridine orange, berberine hydrochloride, and tetracycline on all the hydrochar samples at an initial concentration of $0.3 \mathrm{mg} / \mathrm{mL}$ at $25^{\circ} \mathrm{C}$. Post-treatment clearly affects the adsorption abilities of the hydrochars for different organics; however, there was no simple linear relationship between the 
adsorption capacities of the adsorbates and the quantitative physical and chemical properties of the adsorbents.

The adsorptive capacities of tetracycline on all the hydrochar samples ranged from $294 \mathrm{mg} / \mathrm{g}$ to $419 \mathrm{mg} / \mathrm{g}$, while HHP1 exhibited a higher adsorption efficiency than the other samples. The higher BET surface area (Table 2) and rich surface functional groups (Fig. 1) of HHP 1 would be favorable for providing more adsorption sites and forming hydrogen bonds for tetracycline. Additionally, HHP 1 has quite a negative surface, which might assist the electrostatic interaction between the hydrochar's surface and the positively charged functional groups of the amphoteric tetracycline. These could result in a higher adsorption capacity. Likewise, other samples also showed similar adsorption capacity towards tetracycline.

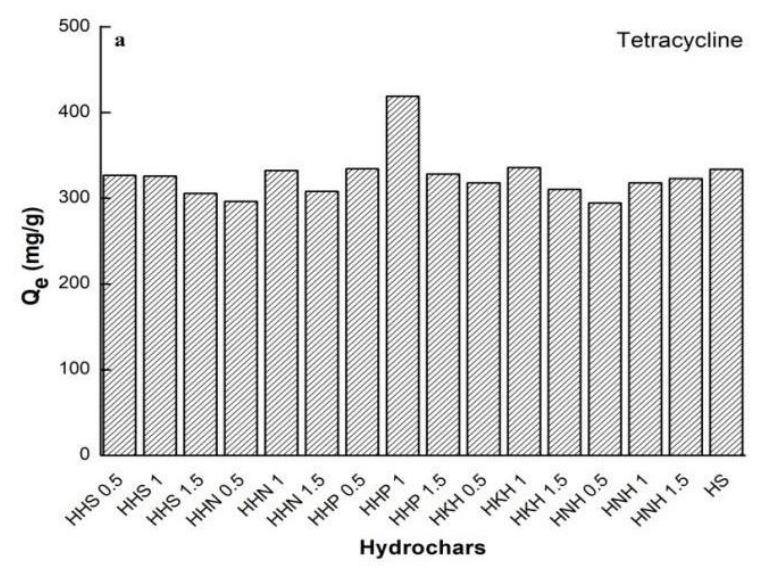

(a)

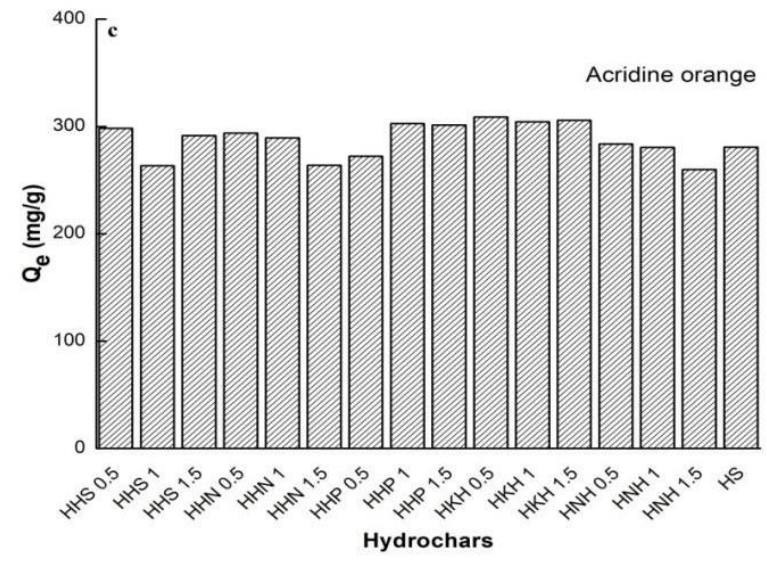

(c)

Fig. 6. Adsorption capacity of tetracycline (a), berberine hydrochloride (b), acridine orange (c), and Congo red (d) on the hydrochar samples at $25^{\circ} \mathrm{C}$

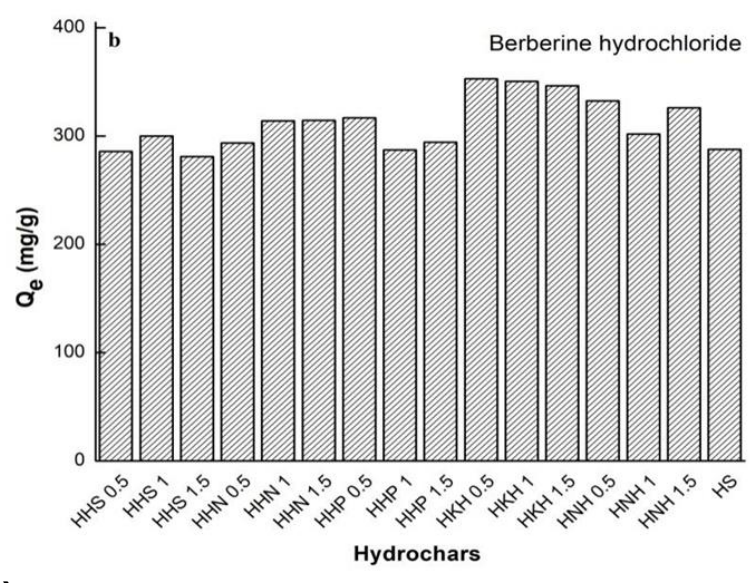

(b)

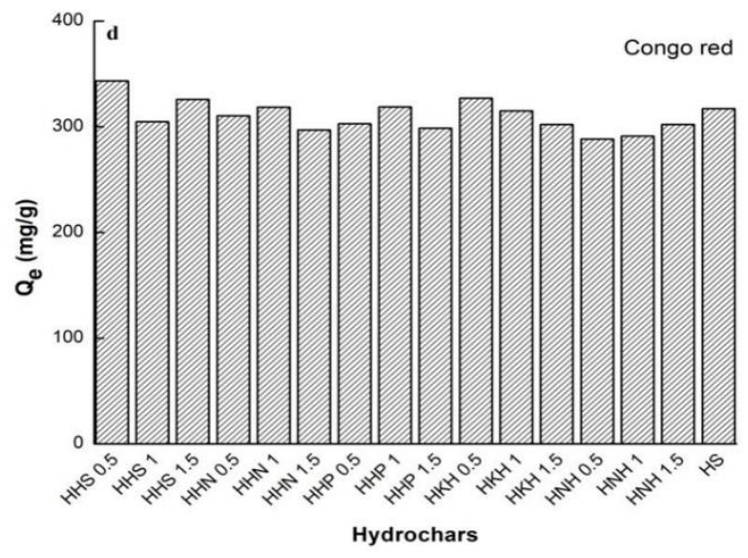

(d) 
The adsorption amounts of berberine hydrochloride and acridine orange on all the hydrochar samples ranged from 281 to $352 \mathrm{mg} / \mathrm{g}$ and 259 to $308 \mathrm{mg} / \mathrm{g}$, respectively, and HKH 0.5 showed the highest adsorption capabilities for both; the combined effect of surface area, functional groups, and surface charge might lead to the highest adsorption capacities of the two organics on HKH 0.5. The adsorption capacities of Congo red ranged from $283 \mathrm{mg} / \mathrm{g}$ to $343 \mathrm{mg} / \mathrm{g}$, while HHS 0.5 showed a higher adsorption efficiency than the other hydrochar samples. Since Congo red could ionize in a wild $\mathrm{pH}$ range $(>5.5)$ to become an anion in aqueous solutions (Olusegun et al. 2020), and HHS 0.5 exhibits negative surface charge and high oxygen content (Table 2), ion exchange action and hydrogen bonds formed between the oxygen containing groups on the adsorbent's surface and Congo red should be the main reasons for the higher adsorption capacity. In summary, post-treatment using acid and base can affect the surface chemistry, such as functional groups, surface area, and zeta potential of hydrochars, thus changing the chemical interactions between hydrochars and organic adsorbates, and it provides different effects on the adsorption capabilities of hydrochars for organics. Among all these hydrochar samples, HKH 0.5 showed a higher adsorption capability for all the model organics; therefore, it was chosen for further experiments.

\section{Adsorption Isotherms}

Figure 7 shows the adsorption isotherm data and fitting curves of the organics onto $\mathrm{HKH} 0.5$ at 25,35 , and $45^{\circ} \mathrm{C}$. The adsorption capacity of tetracycline and berberine hydrochloride onto HKH 0.5 increased with increasing temperature, while acridine orange and Congo red displayed similar adsorption capacities at different temperatures. These results imply chemisorption or strong physical interaction involved adsorption mechanism for all the organics, which might be attributed to the electron donor-acceptor (EDA) interaction (Ambaye et al. 2020), ion exchange (Chen et al. 2018; Ambaye et al. 2020), and hydrogen bonding interaction between the hydrochars and the organics.

Langmuir and Freundlich sorption isotherm were tested to fit the isotherm data as,

$$
\begin{aligned}
& \text { Langmuir model: } \frac{C_{\mathrm{e}}}{Q_{\mathrm{e}}}=\frac{1}{K_{\mathrm{L}} \times Q_{\mathrm{m}}}+\frac{C_{\mathrm{e}}}{Q_{\mathrm{m}}} \\
& \text { Freundlich model: } \log Q_{\mathrm{e}}=\log K_{\mathrm{F}}+\frac{1}{n} \log C_{\mathrm{e}}
\end{aligned}
$$

where $Q_{\mathrm{m}}(\mathrm{mg} / \mathrm{g})$ is the maximum amount of adsorbate adsorbed on the hydrochars, $K_{\mathrm{L}}$ $(\mathrm{mL} / \mathrm{mg})$ is the Langmuir constant related to the affinity of binding sites (Sun et al. 2015). Additionally, $K_{\mathrm{F}}\left((\mathrm{mg} / \mathrm{g})(\mathrm{mL} / \mathrm{mg})^{1 / \mathrm{n}}\right)$ and $1 / n$ are the Freundlich constants indicating relative adsorption capacity and favorability of the adsorption, respectively. Adsorption is favorable when the $1 / n$ values range from 0.1 to 1 ( $\mathrm{Li}$ et al. 2018). 


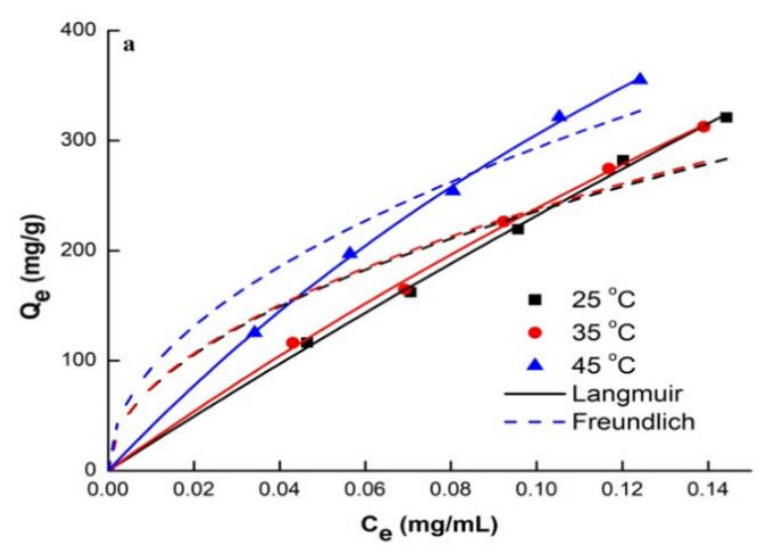

(a)

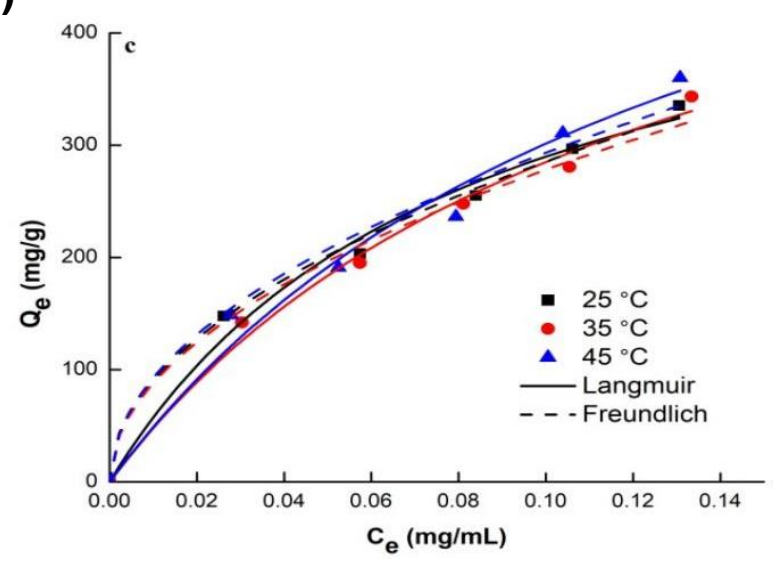

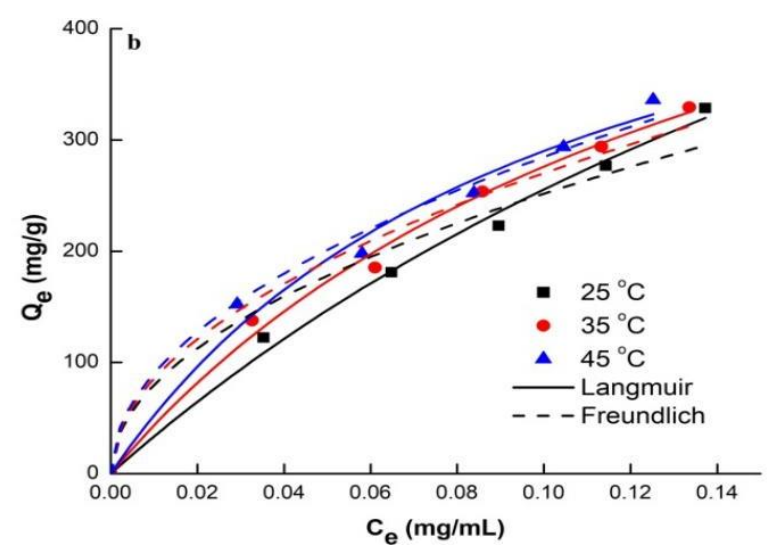

(b)

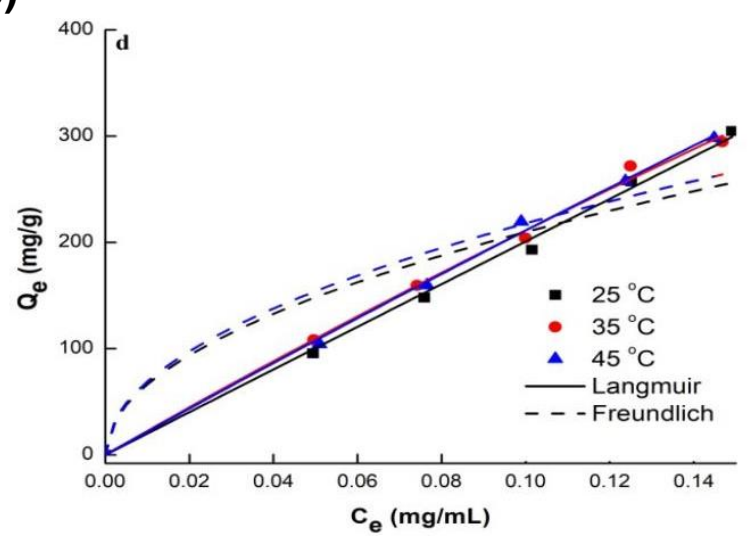

(d)

(c)

Fig. 7. Adsorption isotherm of tetracycline (a), berberine hydrochloride (b), acridine orange (c), and Congo red (d) on $\mathrm{HKH} 0.5$ at 25,35 , and $45^{\circ} \mathrm{C}$

The fitting parameters are summarized in Table S1. The results showed that the Langmuir model was a better fit than the Freundlich model for the adsorption of acridine orange, tetracycline, and berberine hydrochloride with $\mathrm{R}^{2}$ value ranges from 0.986 to 0.984 , 0.998 to 0.999 , and 0.980 to 0.991 , respectively, indicating monolayer adsorption of those organics, which confirmed the chemical adsorption mechanism for the three organics on the hydrochar samples (Parshetti et al. 2014; Shi et al. 2018). Furthermore, the maximum adsorption capacities calculated from the Langmuir equation for acridine orange and tetracycline decreased from 984.7 and $3146 \mathrm{mg} / \mathrm{g}$ at $25^{\circ} \mathrm{C}$ to 585.4 and $1172 \mathrm{mg} / \mathrm{g}$ at 45 ${ }^{\circ} \mathrm{C}$, respectively, indicating that the adsorption of those organics on HKH 0.5 favored lower temperatures, signifying an exothermic process, and these suggest that physical adsorption should still be the dominant mechanism. Additionally, the adsorption of Congo red generated linear isotherms (Fig. 7), which obviously cannot be fitted by the Langmuir model, signifying a partition involved mechanism (Chen et al. 2008), which could occur on the non-carbonized fraction of the hydrochar.

Adsorption thermodynamic parameters for Congo red, acridine orange, berberine hydrochloride, and tetracycline on HKH 0.5 , including Gibbs free energy $\left(\Delta G^{\circ}, \mathrm{kJ} / \mathrm{mol}\right)$, entropy $\left(\Delta S^{\circ}, \mathrm{kJ} / \mathrm{mol} . \mathrm{K}\right)$, and enthalpy $\left(\Delta H^{\circ}, \mathrm{kJ} / \mathrm{mol}\right)$ were calculated based on the Van't Hoff equation at 25,35 , and $45^{\circ} \mathrm{C}(\mathrm{Li}$ et al. 2017), and the values are presented in Table 3. The $\Delta G^{\circ}$ values for all the organics at tested temperatures were less than zero and fell in the range of -20 to $0 \mathrm{~kJ} / \mathrm{mol}$, indicating a spontaneous and mainly physical process of the 
adsorption for these adsorbates (Liu and Zhang 2009). Meanwhile, $\Delta G^{\circ}$ values for all the adsorbates decreased as the temperature was increased, implying a higher adsorption trend at higher temperatures ( $\mathrm{Li}$ et al. 2019a). The positive values of $\Delta S^{\circ}$ for Congo red, acridine orange, and tetracycline indicated an increase in randomness at the solid-liquid interface. The negative $\Delta H^{\circ}$ values for Congo red, acridine orange, and tetracycline showed an exothermic adsorption process, indicating an adsorption mechanism dominated by physical adsorption. The negative value of $\Delta S^{\circ}$ for berberine hydrochloride indicated that the solidliquid interface became less disordered during the adsorption process, which could occur when the adsorption process is controlled by electrostatic adsorption and complexation (Shi et al. 2018). The value of $\Delta H^{\circ}$ for berberine hydrochloride was slightly negative; however, the experimental data displayed an increase in adsorption capacity along with increasing temperature, which suggested an endothermic adsorption process; the error should be due to the minimal absolute value of $\Delta H^{\circ}$ for berberine hydrochloride.

Table 3. Thermodynamic Parameters for Adsorption of Organics on to HKH 0.5

\begin{tabular}{|c|c|c|c|c|c|c|}
\hline \multirow[t]{2}{*}{ Sample } & \multirow[t]{2}{*}{ Model Compound } & \multicolumn{3}{|c|}{$\Delta G^{\circ}(\mathrm{kJ} / \mathrm{mol})$} & \multirow{2}{*}{$\begin{array}{c}\Delta H^{\circ} \\
(\mathrm{KJ} / \mathrm{mol})\end{array}$} & \multirow{2}{*}{$\begin{array}{c}\Delta S^{\circ} \\
(\mathrm{KJ} / \mathrm{mol} . \mathrm{K})\end{array}$} \\
\hline & & $25^{\circ} \mathrm{C}$ & $35^{\circ} \mathrm{C}$ & $45^{\circ} \mathrm{C}$ & & \\
\hline $\begin{array}{l}\text { HKH } \\
0.5\end{array}$ & Congo red & -4.999 & -5.233 & -5.377 & -0.0189 & 0.6168 \\
\hline $\begin{array}{l}\text { HKH } \\
0.5\end{array}$ & Acridine orange & -5.215 & -5.457 & -5.700 & -0.0242 & 1.9983 \\
\hline $\begin{array}{l}\text { HKH } \\
0.5\end{array}$ & $\begin{array}{c}\text { Berberine } \\
\text { hydrochloride }\end{array}$ & -5.361 & -5.489 & -5.691 & -0.0165 & -0.435 \\
\hline $\begin{array}{c}\text { HKH } \\
0.5\end{array}$ & Tetracycline & -5.101 & -5.304 & -5.595 & -0.0247 & 2.2763 \\
\hline
\end{tabular}

\section{Effect of $\mathrm{pH}$}

The $\mathrm{pH}$ value is an important parameter in the adsorption process, as it can affect the form of surface functional groups on the hydrochars and impact the ionic state of the adsorbates in aqueous solutions. Figure 8 shows the zeta potential of HKH 0.5 and the adsorption capacities of all the organics on $\mathrm{HKH} 0.5$ at different $\mathrm{pH}$ values. The surface charges of HKH 0.5 were negative at all the $\mathrm{pH}$ values, and the negative surface charge increased with increasing $\mathrm{pH}$ value.

The adsorption abilities of HKH 0.5 for all the four organics increased with raising $\mathrm{pH}$ values from 2 to 14 . The ionic species of the adsorbates varies at different $\mathrm{pH}$ values, at acidic $\mathrm{pH}$, tetracycline and Congo red dominantly exist in cationic form and all of them could exist in anionic form at alkaline $\mathrm{pH}$ (Olusegun et al. 2020). Since the electrostatic repulsion between the anions and the negatively charged surface of HKH 0.5 didn't lead to a decrease in adsorption capacity, the adsorption of the adsorbates on HKH 0.5 at higher $\mathrm{pH}$ values might mainly through hydrogen bonds and ion exchange action (Teixidó et al. 2011). 


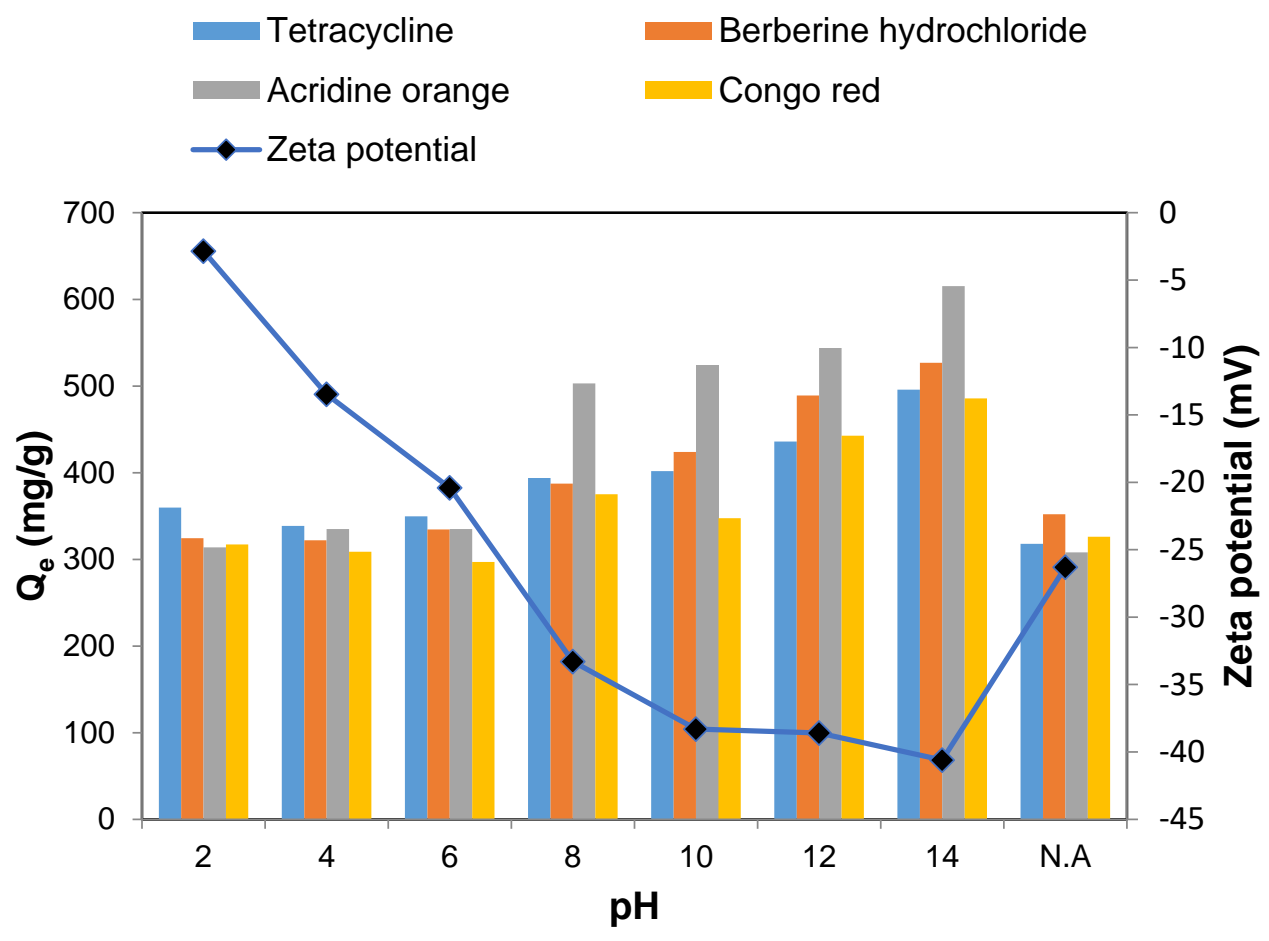

Fig. 8. The effect of initial pH on Zeta potential of $\mathrm{HKH} 0.5$ and adsorption of all organics

\section{Adsorption Kinetics}

Figure 9 shows the adsorption kinetics of Congo red, acridine orange, berberine hydrochloride, and tetracycline onto $\mathrm{HKH} 0.5$ at 25,35 , and $45^{\circ} \mathrm{C}$. It can be seen that all the organics were quickly adsorbed by HKH 0.5 , and approximately $100 \%, 100 \%, 100 \%$, and $99.7 \%$ of the equilibrium adsorption amounts could be reached during the first $10 \mathrm{~min}$ at $25{ }^{\circ} \mathrm{C}$ for acridine orange, Congo red, tetracycline, and berberine hydrochloride, respectively. The rapid increase in adsorption at the initial stage shows the availability of active surface sites, which might be attributed to the underdeveloped inner surface of the hydrochar (Ghanim et al. 2020). Furthermore, no noticeable difference could be observed in the time needed to reach equilibrium at different temperatures.

The adsorption kinetics data were analyzed by pseudo-first-order and pseudosecond-order models as,

$$
\begin{aligned}
& \text { Pseudo-first-order: } \frac{1}{Q_{\mathrm{t}}}=\frac{K_{1}}{q_{\mathrm{e}}}(1+t)+\frac{1}{q_{\mathrm{e}}} \\
& \text { Pseudo-second-order: } \frac{t}{Q_{\mathrm{t}}}=\frac{1}{K_{2} \times q_{\mathrm{e}}^{2}}+\frac{1}{q_{\mathrm{e}} \times t}
\end{aligned}
$$

where $q_{\mathrm{e}}(\mathrm{mg} / \mathrm{g})$ is the calculated adsorbed quantity at equilibrium, and $K_{1}(1 / \mathrm{min})$ and $K_{2}$ $(\mathrm{g} /(\mathrm{mg} \mathrm{min}))$ are the pseudo-first-order and the pseudo-second-order rate constants (Petrović et al. 2016; Ghanim et al. 2020). 


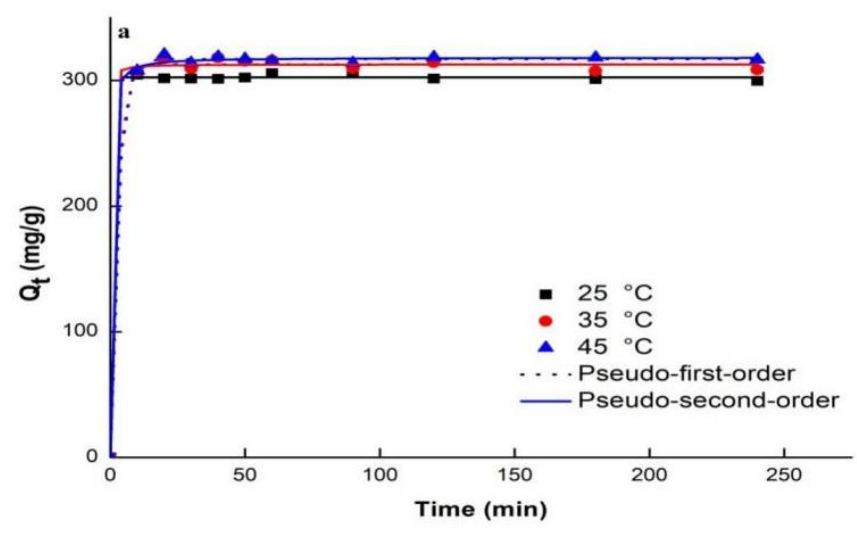

(a)

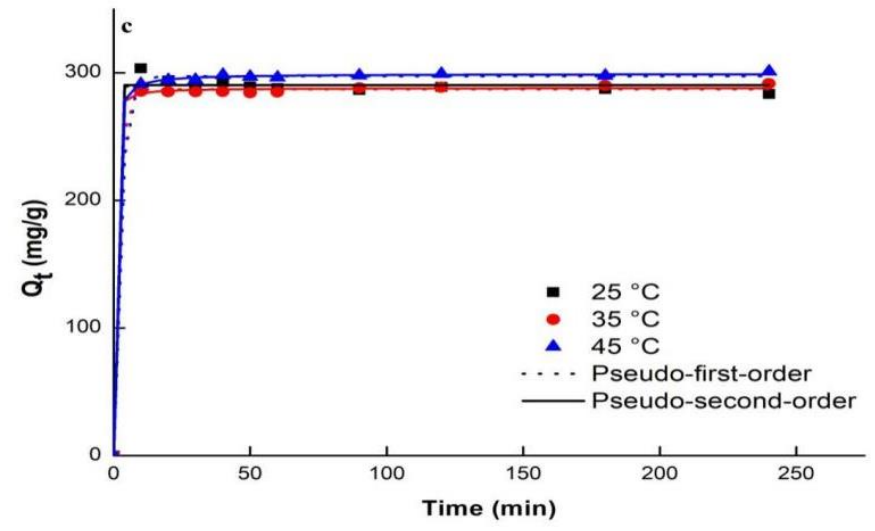

(c)

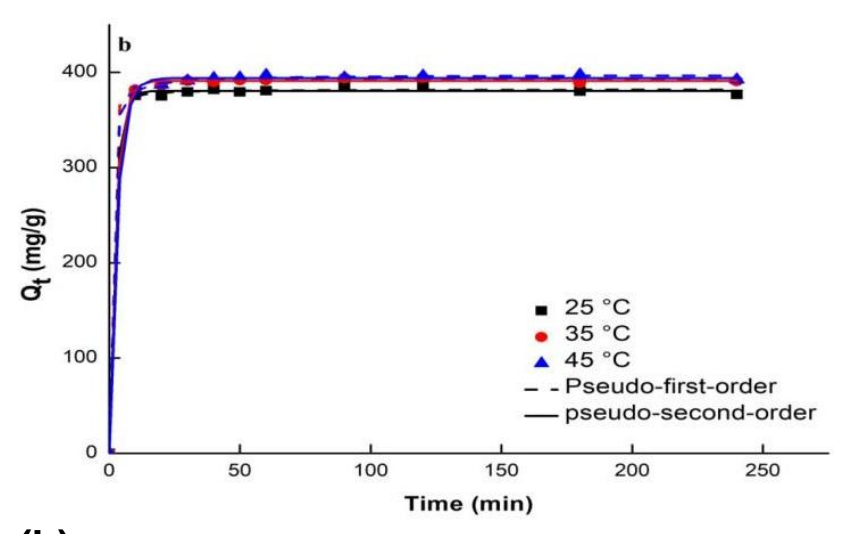

(b)

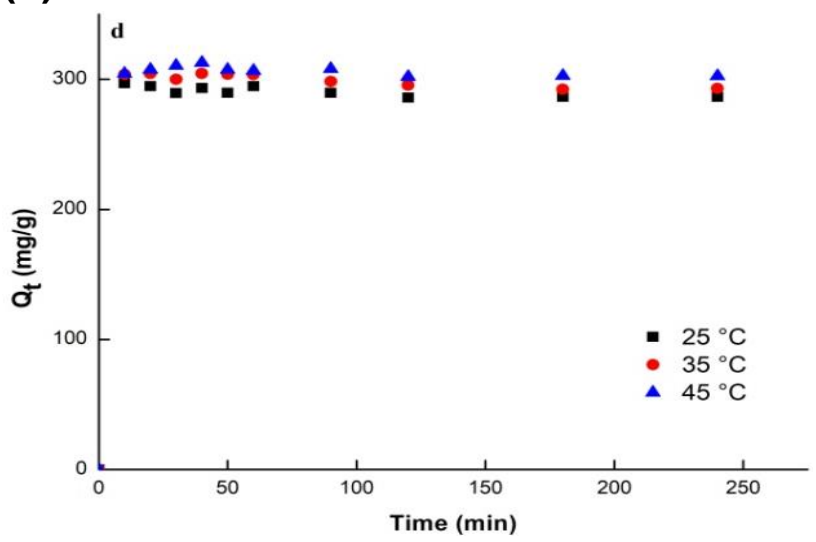

(d)

Fig. 9. Adsorption kinetics of tetracycline (a), berberine hydrochloride (b), acridine orange (c), and Congo red (d) on hydrochar sample $\mathrm{HKH} 0.5$ at 25,35 , and $45^{\circ} \mathrm{C}$

It is notable that some kinetic data (adsorption of tetracycline and acridine orange at $25{ }^{\circ} \mathrm{C}$ and Congo red at all three temperatures) could not be fitted by both the equations. The hydrochar has a quite low BET surface area and small pore volume, and the undeveloped inner surface implied that the organics' adsorption should mainly occur on the outer surface. Therefore, it is not difficult to understand that intraparticle diffusion would not be the rate-controlling step of the adsorption process, and the very fast adsorption rate might lead to the failure of model fitting. From the calculated kinetic parameters presented in Table S2, the pseudo-second-order model was slightly better than the pseudo-first-order model for fitting the adsorption kinetics of berberine hydrochloride, tetracycline, and acridine orange.

\section{CONCLUSIONS}

1. The post-treated rice husk hydrochars had rich oxygen-containing functional groups and negative charges on their surfaces; their carbon and oxygen contents were in the range of $37.4 \%$ to $44.7 \%$ and $29.9 \%$ to $38.6 \%$, respectively, and their BET surface areas were between 1.74 and $12.18 \mathrm{~m}^{2} / \mathrm{g}$. The post-treatment agents and their concentrations influenced some of the physico-chemical properties of the hydrochars, such as the distribution of surface O-containing functional groups. 
2. The adsorption of model organics on the hydrochars was fast, and the highest adsorption capacities for Congo red, berberine hydrochloride, tetracycline, and acridine orange were $327,353,336$, and $309 \mathrm{mg} / \mathrm{g}$, respectively, at $0.3 \mathrm{mg} / \mathrm{mL}$ and $25^{\circ} \mathrm{C}$.

3. The results suggest that post-treatment could be a simple method to modify hydrochars' surfaces for the application of adsorptive removal of organic contaminants from water.

\section{ACKNOWLEDGMENTS}

This work was supported by the Science Foundation Project of Zhejiang University of Science and Technology (Grant No. 2021QN038), the Talent Training Project in 2019 of Zhejiang Provincial Association of Science and Technology (Grant No. SKX201901), and the Zhejiang Provincial Key Research and Development Plan of China (Grant No. 2020C01017).

\section{REFERENCES CITED}

Ambaye, T. G., Vaccari, M., van Hullebusch, E. D., Amrane, A., and Rtimi, S. (2020). "Mechanisms and adsorption capacities of biochar for the removal of organic and inorganic pollutants from industrial wastewater," Int. J. Environ. Sci. Technol. 18, 3273-3294. DOI: 10.1007/s13762-020-03060-w

Azimi, A., Azari, A., Rezakazemi, M., and Ansarpour, M. (2017). "Removal of heavy metals from industrial wastewaters: A review," ChemBioEng Reviews. 4(1), 3759. DOI:10.1002/cben.201600010

Bashir, S., Zhu, J., Fu, Q., and Hu, H. (2018). "Comparing the adsorption mechanism of $\mathrm{Cd}$ by rice straw pristine and KOH-modified biochar," Environ. Sci. Pollut. Res. 25(12), 11875-11883. DOI: 10.1007/s11356-018-1292-Z

Chawla, S., Uppal, H., Yadav, M., Bahadur, N., and Singh, N. (2017). "Zinc peroxide nanomaterial as an adsorbent for removal of Congo red dye from waste water," Ecotox. Environ. Safe. 135, 68-74. DOI: 10.1016/j.ecoenv.2016.09.017

Chen, B., Zhou, D., and Zhu, L. (2008). "Transitional adsorption and partition of nonpolar and polar aromatic contaminants by biochars of pine needles with different pyrolytic temperatures," Environ. Sci. Technol. 42(14), 5137-5143. DOI: $10.1021 / \mathrm{es} 8002684$

Chen, T., Luo, L., Deng, S., Shi, G., Zhang, S., Zhang, Y., Deng, O., Wang, L., Zhang, J., and Wei, L. (2018). "Sorption of tetracycline on $\mathrm{H}_{3} \mathrm{PO}_{4}$ modified biochar derived from rice straw and swine manure," Bioresource Technol. 267, 431-437. DOI: 10.1016/j.biortech.2018.07.074

Darban, A. K., Shahedi, A., Taghipour, F., and Jamshidi-Zanjani, A. (2020). "A review on industrial wastewater treatment via electrocoagulation processes," Curr. Opin. Electrochem. 22,154-169. DOI:10.1016/j.coelec.2020.05.009

Deng, J., Li, X., Wei, X., Liu, Y., Liang, J., Tang, N., Song, B., Chen, X., and Cheng, X. (2019). "Sulfamic acid modified hydrochar derived from sawdust for removal of benzotriazole and $\mathrm{Cu}(\mathrm{II})$ from aqueous solution: Adsorption behavior and mechanism," Bioresource Technol. 290, article ID 121765. DOI: 10.1016/j.biortech.2019.121765 
Fang, J., Zhan, L., Ok, Y. S., and Gao, B. (2018). "Minireview of potential applications of hydrochar derived from hydrothermal carbonization of biomass," J. Ind. Eng. Chem. 57, 15-21. DOI: 10.1016/j.jiec.2017.08.026

Gao, Y., Li, Y., Zhang, L., Huang, H., Hu, J., Shah, S. M., and Su, X. (2012).

"Adsorption and removal of tetracycline antibiotics from aqueous solution by graphene oxide," J. Colloid. Interf. Sci. 368(1), 540-546. DOI:

10.1016/j.jcis.2011.11.015

Ghanim, B., O’Dwyer, T. F., Leahy, J. J., Willquist, K., Courtney, R., Pembroke, J. T., and Murnane, J. (2020). "Application of $\mathrm{KOH}$ modified seaweed hydrochar as a biosorbent of Vanadium from aqueous solution: Characterisations, mechanisms and regeneration capacity," J. Environ. Chem. Eng 8(5), article ID 104176. DOI: 10.1016/j.jece. 2020.104176

Huang, H., Tang, J., Gao, K., He, R., Zhao, H., and Werner, D. (2017). “Characterization of $\mathrm{KOH}$ modified biochars from different pyrolysis temperatures and enhanced adsorption of antibiotics," RSC Adv. 7(24), 14640-14648. DOI: 10.1039/C6RA27881G

Jian, X., Zhuang, X., Li, B., Xu, X., Wei, Z., Song, Y., and Jiang, E. (2018). "Comparison of characterization and adsorption of biochars produced from hydrothermal carbonization and pyrolysis," Environ. Technol. Innov. 10, 27-35. DOI: 10.1016/j.eti.2018.01.004

Lei, Y., Su, H., and Tian, R. (2016). "Morphology evolution, formation mechanism and adsorption properties of hydrochars prepared by hydrothermal carbonization of corn stalk," RSC Adv. 6(109), 107829-107835. DOI: 10.1039/c6ra21607b

Li, B., Lv, J., Guo, J., Fu, S., Guo, M., and Yang, P. (2019a). "The polyaminocarboxylated modified hydrochar for efficient capturing methylene blue and $\mathrm{Cu}$ (II) from water," Bioresource Technol. 275, 360-367. DOI: 10.1016/j.biortech.2018.12.083

Liu, L., Li, Y., and Fan, S. (2019). "Preparation of $\mathrm{KOH}$ and $\mathrm{H}_{3} \mathrm{PO}_{4}$ modified biochar and its application in methylene blue removal from aqueous solution," Processes 7(12), article no. 891. DOI: 10.3390/pr7120891

Liu, Z., and Zhang, F. (2009). "Removal of lead from water using biochars prepared from hydrothermal liquefaction of biomass," J. Hazard. Mater. 167(1-3), 933-939. DOI: 10.1016/j.jhazmat.2009.01.085

Li, Y., Meas, A., Shan, S., Yang, R., Gai, X., Wang, H., and Tsend, N. (2018). "Hydrochars from bamboo sawdust through acid assisted and two-stage hydrothermal carbonization for removal of two organics from aqueous solution," Bioresource Technol. 261, 257-264. DOI: 10.1016/j.biortech.2018.03.108

Li, Y., Tang, S., Bao, Y., Shan, S., Yang, R., Mao, J., Zhu, J., and Ge, Q. (2017). "Adsorption of three flavonoids from aqueous solutions onto mesoporous carbon," $J$. Chem. Eng. Data. 62(10), 3178-3186. DOI: 10.1021/acs.jced.7b00268

Li, Y., Tsend, N., Li, T., Liu, H., Yang, R., Gai, X., Wang, H., and Shan, S. (2019b). "Microwave assisted hydrothermal preparation of rice straw hydrochars for adsorption of organics and heavy metals," Bioresource Technol. 273, 136-143. DOI: 10.1016/j.biortech.2018.10.056

M-Ridha, M. J., Hussein, S. I., Alismaeel, Z. T., Atiya, M. A., and Aziz, G. M. (2020). "Biodegradation of reactive dyes by some bacteria using response surface methodology as an optimization technique, " Alexandria Eng. J. 59, 3551- 
3563. DOI:10.1016/j.aej.2020.06.001

Nakason, K., Panyapinyopol, B., Kanokkantapong, V., Viriya-empikul, N., Kraithong, W., and Pavasant, P. (2018). "Hydrothermal carbonization of unwanted biomass materials: Effect of process temperature and retention time on hydrochar and liquid fraction," J. Energy. Inst. 91(5), 786-796. DOI: 10.1016/j.joei.2017.05.002

Oladipo, A. A., and Ifebajo, A. O. (2018). "Highly efficient magnetic chicken bone biochar for removal of tetracycline and fluorescent dye from wastewater: Two-stage adsorber analysis," J. Environ. Manag. 209, 9-16. DOI:

10.1016/j.jenvman.2017.12.030

Olusegun, S. J., and Mohallem, N. D. S. (2020). "Comparative adsorption mechanism of doxycycline and Congo red using synthesized kaolinite supported $\mathrm{CoFe}_{2} \mathrm{O}_{4}$ nanoparticles," Environ. Pollut. 260, article no. 114019. DOI: 10.1016/j.envpol.2020.114019

Parshetti, G. K., Hoekman, S. K., and Balasubramanian, R. (2013). "Chemical, structural and combustion characteristics of carbonaceous products obtained by hydrothermal carbonization of palm empty fruit bunches," Bioresource Technol. 135, 683-689. DOI: 10.1016/j.biortech.2012.09.042

Parshetti, G. K., Chowdhury, S., and Balasubramanian, R. (2014). "Hydrothermal conversion of urban food waste to chars for removal of textile dyes from contaminated waters," Bioresource Technol. 161, 310-319. DOI:

10.1016/j.biortech.2014.03.087

Petrović, J. T., Stojanović, M. D., Milojković, J. V., Petrović, M. S., Šoštarić, T. D., Laušević, M. D., and Mihajlović, M. L. (2016). "Alkali modified hydrochar of grape pomace as a perspective adsorbent of $\mathrm{Pb} 2+$ from aqueous solution," J. Environ. Manage. 182, 292-300. DOI: 10.1016/j.jenvman.2016.07.081

Ren, M., Song, Y., Xiao, S., Zeng, P., and Peng, J. (2011). “Treatment of berberine hydrochloride wastewater by using pulse electro-coagulation process with $\mathrm{Fe}$ electrode," Chem. Eng. J. 169(1), 84-90. DOI: 10.1016/j.cej.2011.02.056

Shi, Y., Zhang, T., Ren, H., Kruse, A., and Cui, R. (2018). "Polyethylene imine modified hydrochar adsorption for chromium (VI) and nickel (II) removal from aqueous solution," Bioresource Technol. 247, 370-379. DOI: 10.1016/j.biortech.2017.09.107

Sun, K., Tang, J., Gong, Y., and Zhang, H. (2015). "Characterization of potassium hydroxide $(\mathrm{KOH})$ modified hydrochars from different feedstocks for enhanced removal of heavy metals from water," Environ. Sci. Pollut. Res. 22(21), 1664016651. DOI: $10.1007 / \mathrm{s} 11356-015-4849-0$

Teixidó, M., Pignatello, J. J., Beltrán, J. L., Granados, M., and Peccia, J. (2011). "Speciation of the ionizable antibiotic sulfamethazine on black carbon (biochar)," Environ. Sci. Technol. 45(23), 10020-10027. DOI:10.1021/es202487h

Tsechansky, L., and Graber, E. R. (2014). "Methodological limitations to determining acidic groups at biochar surfaces via the Boehm titration," Carbon 66, 730-733. DOI: 10.1016/j.carbon.2013.09.044

Wang, L., Guo, Y., Zhu, Y., Li, Y., Qu, Y., Rong, C., Ma, X., and Wang, Z. (2010). “A new route for preparation of hydrochars from rice husk," Bioresource Technol. 101(24), 9807-9810. DOI: 10.1016/j.biortech.2010.07.031

Wang, X., Liu, Y., Cui, X., Xiao, J., Lin, G., Chen, Y., Yang, H., and Chen, H. (2020). "Production of furfural and levoglucosan from typical agricultural wastes via pyrolysis coupled with hydrothermal conversion: Infuence of temperature and raw 
materials." Waste Manag. 114, 43-52. DOI: 10.1016/j.wasman.2020.06.045

Yan, Y., Ma, X., Cao, W., Zhang, X., Zhou, J., Liu, Q., and Qian, G. (2018). "Identifying the reducing capacity of biomass derived hydrochar with different post-treatment methods," Sci. Total. Environ. 643, 486-495. DOI: 10.1016/j.scitotenv.2018.06.232

Zbair, M., Anfar, Z., Ahsaine, H. A., El Alem, N., and Ezahri, M. (2018). “Acridine orange adsorption by zinc oxide/almond shell activated carbon composite: Operational factors, mechanism and performance optimization using central composite design and surface modeling," J. Environ. Manage. 206, 383-397. DOI: 10.1016/j.jenvman.2017.10.058

Zhang, S., Zhu, X., Zhou, S., Shang, H., Luo, J., and Tsang, D. (2019a). "Hydrothermal carbonization for hydrochar production and its application," in: Biochar from Biomass and Waste, Y. S. Ok, D. C. W. Tsang, N. Bolan, and J. M. Novak (eds.), Elsevier, Amsterdam, Netherlands, pp. 275-294. DOI: 10.1016/B978-0-12-8117293.00015-7

Zhang, X., Gao, B., Fang, J., Zou, W., Dong, L., Cao, C., and Wang, H. (2019b). "Chemically activated hydrochar as an effective adsorbent for volatile organic compounds (VOCs)," Chemosphere 218, 680-686. DOI: 10.1016/j.chemosphere.2018.11.144

Zou, Y., and Yang, T. (2019). "Rice husk, rice husk ash and their applications," in: Rice Bran and Rice Bran Oil, L. Cheong, and X. Xu (eds.), Academic Press and AOCS Press, Cambridge, MA, USA, pp. 207-246. DOI: 10.1016/B978-0-12-8128282.00009-3

Article submitted: September 9, 2021; Peer review completed: October 23, 2021; Revised version received and accepted: December 2, 2021; Published: December 7, 2021.

DOI: 10.15376/biores.17.1.725-749 


\section{APPENDIX}

\section{Supplemental Material}

Table S1. Parameters from Langmuir and Freundlich Models for the Adsorption of Organics onto HKH 0.5

\begin{tabular}{|c|c|c|c|c|c|c|c|c|}
\hline \multirow[b]{2}{*}{ Sample } & \multirow[b]{2}{*}{ Model compound } & \multirow[b]{2}{*}{$T\left({ }^{\circ} \mathrm{C}\right)$} & \multicolumn{3}{|c|}{ Langmuir } & \multicolumn{3}{|c|}{ Freundlich } \\
\hline & & & $Q_{m}(\mathrm{mg} / \mathrm{g})$ & $K_{\mathrm{L}}(\mathrm{L} / \mathrm{mg})$ & $\mathbf{R}^{2}$ & $K_{\mathrm{F}}(\mathrm{mg} / \mathrm{g})(\mathrm{mL} / \mathrm{mg})^{1 / n}$ & $n$ & $\mathbf{R}^{2}$ \\
\hline \multirow[t]{3}{*}{ HKH 0.5} & Congo red & 25 & - & - & - & 663.5 & 2 & 0.884 \\
\hline & & 35 & 3071 & 0.739 & 0.996 & 688.8 & 2 & 0.921 \\
\hline & & 45 & 5420 & 0.406 & 0.997 & 689.0 & 2 & 0.915 \\
\hline \multirow[t]{3}{*}{ HKH 0.5} & Acridine orange & 25 & 984.7 & 3.504 & 0.994 & 796.3 & 2 & 0.962 \\
\hline & & 35 & 684.9 & 6.755 & 0.994 & 854.6 & 2 & 0.982 \\
\hline & & 45 & 585.4 & 9.829 & 0.986 & 900.2 & 2 & 0.990 \\
\hline \multirow[t]{3}{*}{ HKH 0.5} & Berberine hydrochloride & 25 & 526.5 & 12.24 & 0.988 & 901.7 & 2 & 0.996 \\
\hline & & 35 & 633.6 & 8.172 & 0.991 & 879.5 & 2 & 0.987 \\
\hline & & 45 & 709.4 & 7.391 & 0.980 & 927.2 & 2 & 0.977 \\
\hline \multirow[t]{3}{*}{ HKH 0.5} & Tetracycline & 25 & 3146 & 0.796 & 0.998 & 745.8 & 2 & 0.922 \\
\hline & & 35 & 1677 & 1.658 & 0.998 & 752.7 & 2 & 0.938 \\
\hline & & 45 & 1172 & 3.525 & 0.999 & 927.9 & 2 & 0.954 \\
\hline
\end{tabular}


Table S2. Parameters from Pseudo-First-Order and Pseudo-Second-Order Models for the Adsorption of Organics onto HKH 0.5

\begin{tabular}{|c|c|c|c|c|c|c|c|c|}
\hline \multirow[b]{2}{*}{ Sample } & \multirow[b]{2}{*}{ Model Compound } & \multirow[b]{2}{*}{$T\left({ }^{\circ} \mathrm{C}\right)$} & \multicolumn{3}{|c|}{ Pseudo-first Order } & \multicolumn{3}{|c|}{ Pseudo-second Order } \\
\hline & & & $q_{\mathrm{e}}(\mathrm{mg} / \mathrm{g})$ & $K_{1}(1 / \mathrm{min})$ & $\mathbf{R}^{2}$ & $q_{\mathrm{e}}(\mathrm{mg} / \mathrm{g})$ & $K_{2}(\mathrm{~g} /(\mathrm{mg} \min ))$ & $\mathbf{R}^{2}$ \\
\hline \multirow[t]{3}{*}{ HKH 0.5} & Congo red & 25 & - & - & - & - & - & - \\
\hline & & 35 & - & - & - & - & - & - \\
\hline & & 45 & - & - & - & - & - & - \\
\hline \multirow[t]{3}{*}{ HKH 0.5} & Acridine orange & 25 & - & - & - & - & - & - \\
\hline & & 35 & 287.04 & 0.528 & 0.999 & 288.09 & 0.023 & 0.9994 \\
\hline & & 45 & 297.39 & 0.385 & 0.999 & 299.14 & 0.011 & 0.9998 \\
\hline \multirow[t]{3}{*}{ HKH 0.5} & Berberine hydrochloride & 25 & 380.66 & 0.435 & 0.9993 & 382.15 & 0.014 & 0.9994 \\
\hline & & 35 & 391.19 & 0.369 & 0.9997 & 393.34 & 0.009 & 0.9998 \\
\hline & & 45 & 394.04 & 0.323 & 0.9994 & 397.54 & 0.005 & 0.9998 \\
\hline \multirow[t]{3}{*}{ HKH 0.5} & Tetracycline & 25 & - & - & - & - & - & - \\
\hline & & 35 & 312.90 & 0.402 & 0.9984 & 312.87 & 0.0505 & 0.9981 \\
\hline & & 45 & 317.14 & 0.356 & 0.9995 & 318.33 & 0.0128 & 0.9991 \\
\hline
\end{tabular}

